\title{
Building Inclusive Cities Archive
}

https://citiesofmigration.ca 


\section{Table of Contents}

Building Inclusive Cities

Overview

Civic Inclusion

Cultural Inclusion

Economic Inclusion

Educational Inclusion

Employment Inclusion

Entrepreneurship Inclusion

Financial Inclusion

Health Inclusion

Political Inclusion

Role of Media

Social Inclusion

Spatial Inclusion

Welcome Ability. 


\section{Building Inclusive Cities}

By Mahmoud Bakkar

April 19, 2017

The Building Inclusive Cities project explores the multidimensional and interconnected factors that contribute to open, inclusive cities in an era of global migration.

\section{My City of Migration - A City Diagnostic}

- How inclusive is your city? Take the pulse of your city with the My City of Migration (MyCOM) Diagnostic. MyCOM is a modular web app that helps city and community stakeholders assess 'inclusion factors' across the urban landscape and gain understanding of the conditions that enhance (or inhibit) immigrant inclusion.

\section{Case Studies}

- Case study: The Inclusion of Migrant with Irregular Status [PDF]/ Dr. Sarah Spencer, Director, Global Exchange on Migration and Diversity, COMPAS, University of Oxford (UK). See also, webinar and related resources.

- Case study: Planning for Urban Resilience and Inclusive Cities: Lessons from Toronto [PDF] / Dr. Zhixi Zhuang, School of Urban and Regional Planning, Ryerson University (Toronto). See also, webinar and related resources.

\section{Learning Platform}

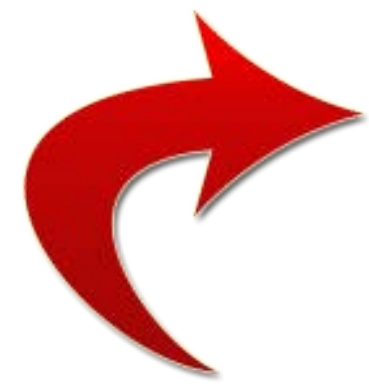

- Explore the challenges and opportunities of inclusive city-building with our international experts. The Building Inclusive Cities essay series provides in-depth analysis on what works, what doesn't, the cost of exclusion, tailored lists of good practices, policy recommendations, and opportunities for peer learning exchange (webinars). Check out our collection of expert essays on major inclusion themes [see sidebar box].

\section{Video: How to Use the MyCOM Diagnostic - take a tour!}




\section{Overview}

\section{By Mahmoud Bakkar}

Cities that aspire to a cosmopolitan reputation on the global stage need to build diversity into their winning formula. Along with efforts to sell their particular "brand" and to compete for investors, new industries or tourism, these cities are investing in welcoming strategies that can attract immigrant skills, talents, and energies. City leadership is essential in helping the wider community to support the idea that a vibrant economic, social, and cultural base can generate the quality of life that international populations seek, and all residents enjoy.

The Building Inclusive Cities (BIC) Learning Platform is anchored by a collection of essays by international experts on themes central to inclusive city-building, including the ten dimensions of inclusion indexed by the MyCOM Diagnostic: economic, cultural, social, health, education, political, civic, spatial, the role of media and the general welcome ability of municipal institutions and public space. Each expert essay provides insight and analysis on building inclusive cities, what works, what doesn't, the cost of exclusion, and include examples of good practice, policy recommendations, and resources for further learning and connection.

Building Inclusive Cities is a two-year project led by Cities of Migration at Ryerson University's Global Diversity Exchange and supported by the Open Society Initiative for Europe, with Bertelsmann Stiftung and other partners. The project builds on the seminal research of the 11-city At Home in Europe Project (Open Society Foundations) and promising local integration practices identified under the central theme, Living Together, at Cities of Migration.

\section{Learn about the MyCOM Diagnostic}

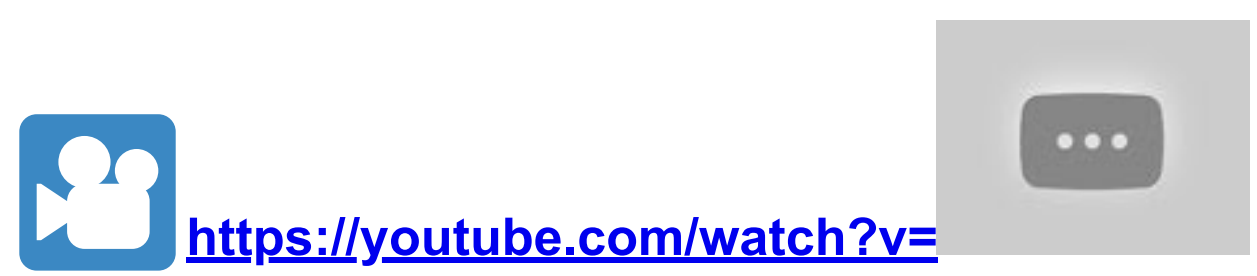




\title{
Civic Inclusion
}

\author{
By Mahmoud Bakkar
}

\section{By Zrinka Bralo, Chief Executive, Migrants Organise}

\section{Integration Is Old News, Just Ask Immigrants}

I have been involved with integration for more than two decades, integrating myself and thousands of other refugees and migrants in my work at Migrants Organise in the UK.

Between 2007 and 2011 we helped more than 3,500 overseas qualified doctors and dentists from 98 countries pass their verification exams and find jobs in the National Health Service, to use much needed skills to help themselves and us. We continue to provide mentoring, English classes, civic leadership academies, undertake voter registration drives and organise Refugee Welcome committees. In short, we are making integration happen every day.

In 2009, I was part of the Independent Asylum Commission, the most comprehensive inquiry about the asylum system ever conducted in the UK. Integration was part of the listening process over the two years we conducted the Inquiry, during which I asked four former Home Secretaries from both main parties about their communications strategy with regards to the dispersal of asylum seekers from London. Introduced in 2001, the dispersal policy. meant that asylum seekers were move to places where the Government decided they should live. Many of these were small towns lacking the infrastructure to support new arrivals.

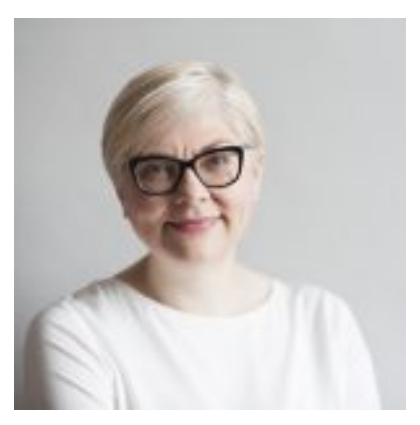

\section{Zrinka Bralo}

Chief Executive, Migrants Organise

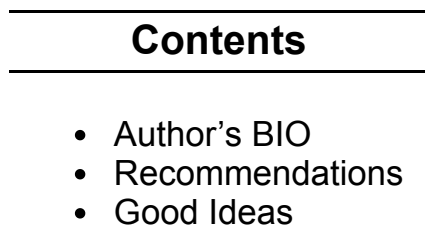

[see_more]

All four former Home Secretaries misunderstood the question. They told me about the leaflets they produced for refugees in various languages. I clarified: "What was their communication strategy for the 'host communities'? Were those communities told who was coming to live there, and why? And were they involved in welcoming new arrivals?"

It was clear from their response that such an approach had never been considered. Integration was simply not part of their policy. It was left instead to under-resourced local authorities to house people, often in abandoned, boarded-up estates. In many areas, it was left to civil society groups to support those left destitute, isolated out of sight and prevented from working, claiming welfare benefits, going to university, or even volunteering. Across the board, an acute lack of access to proper legal advice, English classes and proper healthcare (especially the specialist care for trauma suffered by many asylum seekers) left many in an extremely vulnerable position.

\section{Integration is a two-way street}

Integration didn't make it on to the news then, and it doesn't now unless something bad happens. When horrible terrorist attacks happen some sections of the press investigate the origins of the attackers and search for clues for their senseless acts in their lack of belonging, in being foreign. The debate quickly spirals into what immigrants should be doing to integrate, and very often that boils down to learning English and/or respecting British values.

There is nothing wrong with saying that immigrants should learn English. Of course, language skills are necessary to enable people to thrive in their new neighborhoods, new jobs and new lives. The question is - is it really necessary to keep saying it, while restricting access to it and isolating people? Especially if it is done in a way that leaves the public with an impression that, for some unexplained reason, immigrants don't want to learn English. Nothing could be further from the truth, but as we are now living in 'post-truth' era, how do we have a real, honest, facts-based conversation about integration? How does integration happen? What does it look like? And who should be doing what to make it happen? How has Britain, an island of migrants, dealt with integration in the past?

Amongst many others, Migrants Organise have been 'integrators' for more than 24 years. We know that integration is a little different for each person and it needs to be a two-way process. Some people need help with English, some with finding jobs, others with accessing further education or verifying their overseas qualifications, and all need help in navigating the complex, hostile and unwelcoming bureaucracies. 
Simple things, such as opening a bank account is challenging and mission impossible if you are a refugee. Banks will not accept biometric cards issued by the government as a valid ID, notwithstanding the success of programs like the municipal $\underline{I D}$ in a growing number of U.S. cities. For EU migrants, navigating and filling in complex and long forms to acquire residency permits is a nightmare. Renting a place to live or going to hospital is now part of the immigration control process. Private landlords are required to check your immigration status to make sure you are not 'illegal'. Banks have to check bank accounts of existing customers to make sure that you are not 'illegal'. Local doctors and hospitals have to check that you are not 'illegal'. Universities and employers have immigration compliance officers to check that you are not 'illegal'. Your child will come home from school with a form asking you to declare their country of birth. While a growing number of cities are taking a stand on protecting the rights of the most vulnerable, and ensuring access to services, there is no guarantee you will not be spared the humiliation of exclusion and dehumanisation when you arrive in the UK.

\section{Cost of exclusion}

The Grenfell Tower fire which has happened in our neighbourhood has exposed some of the neglect and hostility in the most cruel way. Many of the victims and survivors are immigrants, and several of them undocumented. They lost everything, but are reluctant to come forward to seek help even after the government offered to give them some form of limited status. For all intents and purposes, they are invisible.

To make things worse, many people who have to perform all these checks in public services have no idea what they are supposed to do, so they begin to suspect your 'foreign' sounding name or your 'otherness' - the fact that you 'look a bit foreign'. By doing this they create barriers and daily indignities for all minorities. The experience that is now a reality for more than one third of Londoners who are immigrants.

Nothing in your daily experience of life as an immigrant says - 'you are welcome here'. The actual social spaces and social situations in which you can experience the other side of integration - the welcome from your new country - has shrunk to a few community organisations and faith institutions. All other interactions with social infrastructure systems are, at best, neutral and, at worst, and obstructive. If you are healthy, if you work, and have a place to live, you will accept these daily obstacles and find a way to manage and make the best of these opportunities. All the while, you can ignore the negative media headlines blaming you for stealing jobs, causing congestions on motorways, and chastising you for 'not learning English'.

But if anything goes wrong, if you lose your job, if you are exploited, if you get sick, if you are a victim of crime, if you get stuck in immigration system, if you try to find good and affordable legal advice - you enter the twilight zone of forms, bureaucracy, contempt, marginalisation - waiting and more waiting.

The dehumanisation of immigrants has become a regular feature in the public narrative, and since the Brexit vote we have seen dramatic increase of reported hate attacks. There is no such thing as intellectual version of hate - someone always ends up hurt as people take seriously the racism that emerges daily from the front pages of the mainstream media.

\section{Living together}

Every day, here at Migrants Organise, we hear horror stories of injustice from refugees and migrants who turn to us for support. This degrading treatment is the result of hostile policies designed to reduce the number of immigrants in order to appease those who wrongly blame immigrants for the lack of social housing, the failing economy and low wages, the underfunded health service, and the lack of investment in other social infrastructure such as schools.

But, despite all this, integration is happening all the time and both immigrants and British citizens are constantly conspiring to make it work. London, with its superdiversity as its main pull factor, is evidence of integration that happens despite the Government's efforts to make the lives of immigrants difficult.

Immigrants put up with unjust treatment because they have no choice. They turn to their friends and family, to civil society groups, to their neighbors and colleagues at work and in schools, to share their lives, joys and worries and to make the best of it. They are survivors and their receiving communities are the true integrators and the welcome committees.

So here is a revolutionary idea - it is called accountability. The media,_as well as the politicians, could take a long, hard look at themselves and report on what it is that they are doing, or not doing, to advance integration. To analyse how the laws that they have been making and the rhetoric they have been utilising in their efforts to get or remain in power, or to sell newspapers, helps or hinders social integration.

They could start by looking at the impact of harsh immigration polices, stop and search, anti-terrorism prevention policies, cuts to language provision, cuts to legal aid.

As always, the voice that is missing from the debate on immigration and integration is the voice of those that are most affected by it. So, here is another revolutionary idea - if in doubt about whether integration works or what else needs to happen to make it work, ask the experts - migrants and refugees themselves, for us integration is a fact of life, even when it is not newsworthy for politicians and media. 


\section{The Author}

Zrinka Bralo is Chief Executive of Migrants Organise - a community organising platform for migrants and refugees acting for justice. Zrinka is a refugee from Sarajevo (Bosnia), where she was a journalist working with leading war correspondents during the siege in the 90's. She is a founder of the Women on the Move Awards to recognize achievement of migrant and refugee women and winner of the 2011 Voices of Courage Award by the Women's Refugee Commission in New York. She joined their Board in 2012.

Zrinka successfully campaigned to end immigration detention of children and currently campaigns to end indefinite immigration detention. In September 2015 she became founding Chair of the National Refugee Welcome Board, a community sponsorship visa scheme to ensure sanctuary for 20,000 Syrian refugees. She is founding Trustee of the Bridge of Peace, reconciliation charity supporting young people working for peace in North Bosnia, in towns were notorious concentration camps were discovered during the 90's war and children are growing up in the shadow of the worst atrocities committed in Europe since WW2.

Zrinka holds MSc in Media and Communications from London School of Economics and is 2014 Churchill Fellow.

\section{Recommendations:}

- Coming soon

$\bullet$

Top

[/see_more] 


\title{
Cultural Inclusion
}

\author{
By Mahmoud Bakkar
}

\section{By Raheel Mohammed, Founder and Director, Maslaha}

How do you understand a community of people? How do you interpret or translate their words and actions, communicate their fears and hopes for those outside that community?

Any committed translator will describe the sensitivity with which they approach the original text, their sense of awe and responsibility. Does the translation do justice to the original rhythms of the text? to metaphors that are, for example, both witty and deeply insightful? How to maintain the integrity of the author's voice, to ensure the translator's voice does not encroach too much? It is an aesthetic and cultural as well as a technical endeavour.

The poet Mimi Khalvati writes: "Of course, translation involves not only rendering a text, but also negotiating between two cultures. Arguments about the respective merits of foreignization and domestication are endemic and call into question our ethical and aesthetic values."[1]

Do we apply the same level of expertise and sensitivity to issues facing Muslim and other migrant communities and their place in society today? Are their concerns being translated, or interpreted, as they would like? Are we doing justice to complex lives?

[see_more]

The absence of sensitive translation is exposed by traumatic events such as the recent terrorist attacks in Manchester, London, and Barcelona, and the subsequent attacks on innocent Muslims caught up in the collateral damage. The ensuing debates and interviews recycle an all too familiar narrative. Another terrorist act, another layer of media assertion, handwringing Muslims rolled out to dissect their own communities and government policies, Muslim experts crowned and dethroned.

Appropriate "translation" is a fundamental aspect of our work at Maslaha, a response to the lack of appropriate cultural understanding that surrounds us -in public services, organisations, governmental structures. The repercussions of this poor translation is so pervasive, so clichéd, that we risk becoming immune to the vividness and unique character of people's stories. Empty acronyms such as BAME (Black, Asian and Ethnic Minority) that lump all minorities together provide a reassuring security blanket for those organisations and institutions who don't want to venture too close to the messiness of people's lives.

In the context of our work at Maslaha, "bad translation" exacerbates a heightened focus on Muslim communities and Islam across the UK and abroad. In recent years, the combination of terrorist acts, war, and political decisions about how to tackle radicalization have rapidly shaped how Muslims are portrayed and regarded in wider society.

\section{The cost of exclusion}

Muslim communities in the UK context face a daily barrage of violence, discrimination, inequality and stigmatization. Our public services and politicians struggle to differentiate the diversity within Muslim communities; whether they are Somali or Pakistani, Shia or Sunni, or live in Walthamstow or Washwood Heath.

Muslims represent the largest minority faith group in the UK and are an ethnically diverse population with a very young age profile. A significant proportion of this population lives in deprived inner-city areas, and Muslims face higher levels of unemployment, economic inactivity, ill health, educational underachievement, and poor housing conditions, compared to other faith groups.

Criminal Justice System. $22 \%$ of those in Young Offender Institutes describe themselves as Muslim, a rise from $13 \%$ in 2011. Muslim prisoners account for $13.4 \%$ of the prison population yet make up only $4.2 \%$ of the UK population, according to the 2011 Census.

Economic activity. According to the 2011 Census, $17 \%$ of all Muslims between the ages of 16 and 24 are unemployed the highest rate, quite significantly - of any faith group. Across all age and gender groups, $45 \%$ are economically inactive: 
almost 100,000 Muslim men of working age are unemployed, and almost $\underline{400}, \underline{000}$ Muslim men of working age have no qualifications

Health. Muslim communities frequently have trouble accessing health services, and what support exists isn't necessarily relevant or appropriate.[2] Rates of long-term conditions tend to be higher than average in Muslim communities. For example, type 2 diabetes is up to six times more common in South Asian communities in the UK (Pakistani, Bangladeshi and Indian origin).[3] A lack of shared language between patients, communities and health practitioners contributes to challenges in accessing support, and that support being relevant and appropriate. For example, there is no word for conditions like depression, dementia, hepatitis, etc., in many languages, including Arabic, Urdu, Somali, Bengali, Sylheti, Punjabi, and Gujarati.

Gender equality. There is a strong gendered dimension to Islamophobia. [4] Recent figures show a $70 \%$ rise in hate crimes against Muslims in London between 2014-2015. 60\% of these incidences involved women, with women wearing face veils being the victims of the most aggressive attacks.[]ㅡ In the workplace, discrimination against Muslim women means they are $70 \%$ more likely to be unemployed than white Christian women - even when they have the same qualifications and language skills.[]]

\section{For the Common Good}

Maslaha creates new ways of tackling long-standing issues affecting Muslim communities. Our work provides practical alternatives informed by cultural insight and understanding. We combine imagination and craftsmanship to improve services, change attitudes and challenge systems of inequality. We believe that reminding people that Islam can also be synonymous with social justice and charity is an important step towards challenging divisive negative stereotypes.

'Maslaha' itself translates from Arabic as 'for the common good' and this principle lies at the very heart of our work. We use creativity and an innovative approach to bring together a wide and varied group of people to create a movement around addressing a need or celebrating inspiring stories and ideas.

I have chosen some examples of how our projects provide practical and positive support for unheard voices and marginalized communities.

\section{Policy recommendations}

1. Working practically with communities at a grassroots local level. This involves working collaboratively to create resources addressing systemic inequalities that can be picked up and used by local statutory services, for example health services. The diverse nature of a community or city, and complexity of social issues demands input from the whole community if deep change is to take place.

\section{Example: Talking From The Heart}

The award-winning resource, Talking From The Heart (www.talkingfromtheheart.org), tackles depression and anxiety in Somali, Pakistani and Bangladeshi communities, with the aim of widening the language around 'mental health' to better resonate with patients and their families. This involved working practically with communities at a grassroots local level, including AT Medics, London's largest group of NHS clinical practices; Midaye, a Somali community organisation; psychotherapists; imams; musicians; film-makers and community organizations across London. A diverse group of partners helped us develop a practical, innovative mental health resource, despite the fact that there is no word for 'depression' in Arabic, Somali, Sylheti or Urdu. We were also able to mobilize a larger and more varied number of community members on a subject which carries considerable stigma.

Outcome: Talking From the Heart is now used in 7 NHS Trusts and by the leading mental health charity Mind, endorsed by the Royal College of GPs, and included in Kings College School of Medicine's curriculum. The Talking From the Heart resource is used by the Queensland government in Australia and is being picked up increasingly internationally following the project winning the Innovation Mindset Challenge 2014, set by the Rockefeller Foundation and Columbia University.

\section{Changing practice at a local level can only be sustained by sharing our learning at a strategic level and} ensuring that expertise from practical delivery is able to inform future policy decisions. Working with organizations like the NHS, Ministry of Justice, and universities and schools to deliver accessible and inclusive approaches to the widest possible audiences has been an effective way of addressing systemic inequalities in Muslim (or other cultural) communities and influencing future policy decisions.

Our work tackling the root causes of the disproportionate number of young Muslim men in prison developed while working with a community group in Mile End, east London. Over two years, we explored the experiences of young men and the criminal justice system. We ran entrepreneurship workshops and school workshops led by the young men we were working with; collaborated with artist Hannah Habibi Hopkins; and participated in the international Unusual Suspects festival. 
Prior to this work very little research had looked at the experiences of young Muslim men in the criminal justice system. Our report aimed to provide a more complex picture which did not ignore the voices of young Muslim men, and gave them a chance to be heard.

Outcome. The recommendations of our recently published 'Young Muslims on Trial' include delivering training to magistrates and criminal justice professionals so that problems associated with stereotyping can be overcome. The training would be developed and delivered collaboratively with young men who have been in prison.

This is an important step towards redefining who 'experts' are in the eyes of policy makers and encouraging them to see the immense value and expertise of communities who have unique insight and lived experience of areas that are being worked on. Recognizing this knowledge and acting accordingly will mean interventions will be more effective.

3. How to influence the Public Imagination. Wherever possible we aim to influence and shape the public debate and media narrative around Muslim identity through these tools which have proven increasingly important in countering the negative discourse which many Muslim communities feel has been forced upon them.

Creative tools such as film, photography and music inform and develop our practical work. The Talking from The Heart resource incorporates the language of faith and culture using film and music, and cultural figures, concepts and messages (words) that are recognizable to Muslim audiences. For example, Somali musician, Maryam Mursal's songs of exile helped to create a vocabulary around depression.

Example: Muslim Girls Fence project

Muslim Girls Fence uses the sport of fencing to challenge misconceptions of Muslim girls and share new visions of what it means to be a young Muslim in the UK today. We recognize that because of the complex discrimination facing Muslim girls - ranging from the double discrimination they face on the basis of both gender and faith, to the impact of the government's current counter-extremism policies and strong social inequalities in areas such as education - that radical and unusual interventions are urgently needed.

We also understand the need to counter the force of pervasively negative images of Muslim women projected in mainstream media. For this reason the project has also involved the production of an exhibition and short film in an effort to breach a public imagination that is being ever constricted by the media and government preoccupation with a certain type of Muslim woman. The exhibition and film were showcased at the Women Of the World (WOW) festival 2016 at the Southbank Centre, attracting international attention and coverage.

Outcome. The unusual nature of this project means it has fast gained an international audience, meaning that the voices of these young women are being projected on a considerable scale - offering them the opportunity to grow in agency and confidence. The practical element of the project and the ongoing involvement in fencing and conversations around identity has also been central in building resilience and drawing out new skills. Testimony from teachers at the school show that these young girls, many of whom are seen as 'difficult to engage' were not previously being given opportunities to grow and excel. Since the pilot project teachers have noted a couple of girls who had previously been quiet in class, becoming more confident, both in contributing to lessons and also with their peers.

\section{Conclusion}

In The Sense of an Ending, Frank Kermode distinguishes between simple fictions - which he calls 'the opium of the people' - and complex, nuanced fictions of the kind that reveal truths. Complex fictions, he says, not only 'console but make discoveries of the hard truth here and now...we do not feel they are doing this if we cannot see the shadow of the gable, or hear the discoveries of dissonance, the word set against the word'.

Simple fictions create pat narratives that pit 'us' against 'them'. They exclude people; those who don't control the narratives are absent. As in paintings that celebrated Britain's colonial past, the 'others' are just out of frame. Their stories become trite, one-dimensional fictions. They may be at ease with exploring an aspect of another person's identity but the whole is too much trouble to understand.

The same could be said of the repression of rich, powerful, diverse voices that exist in migrant communities.

The right to control our own story is a powerful one, and the story of migrant communities needs new writers, new storytellers. We don't need simple fictions.

[1] Saudade: An Anthology of Fado Poetry, ed. Mimi Khalvati, w. Vasco Graça Moura (Calouste Gulbenkian Foundation)

[2] See e.g. Parliamentary Office of Science \& Technology (2007) Postnote: Ethnicity \& Health, p2; Mind UK (2013) We still need to talk, p19; L D Laird et al (2007) 'Muslim patients and health disparities in the UK and US,' Arch Dis Child Oct; 92(10): 922-926; APPG on Diabetes (2006) Diabetes and the disadvantaged 
[3] K. Khunti et al (2009) Diabetes UK \& South Asian Health Foundation recommendations on diabetes research priorities for British South Asians, p1

[4] http://www.opensocietyfoundations.org/voices/tangled-web-discrimination-faced-muslim-women

[ㅁ] http://www.bbc.co.uk/news/uk-england-london-34138127

[] http://www.independent.co.uk/news/uk/home-news/british-muslim-women-71-more-likely-to-be-unemployed-due-toworkplace-discrimination-10179033.html

\section{The Author}

Raheel Mohammed is the founder and director of Maslaha and has recently been profiled as one of Britain's 50 New Radicals in The Observer newspaper for pioneering creative change to some of society's most difficult issues.

He has created award-winning resources which tackle inequalities in areas such as health, education, the role of women in Islam, and the historical relationship between Islam and Europe. Maslaha's award-winning health work is now used locally, nationally, and internationally and seen as examples of good practice and innovative in its use of technology. . Raheel helped set up and was the Assistant Director at the award-winning Crossway Foundation, advising on and initiating education programmes designed to raise awareness of Middle East and Muslim cultures through art. He is an awardwinning journalist and he has also completed a unique executive education programme focusing on entrepreneurship at Columbia Business School.

\section{Recommendations:}

- Working practically with communities at a grassroots local level. This involves working collaboratively to create resources addressing systemic inequalities that can be picked up and used by local statutory services, for example health services. The diverse nature of a community or city, and complexity of social issues demands input from the whole community if deep change is to take place.

- Changing practice at a local level can address systemic inequalities and provide sustainable solutions when lessons learned and expertise from practical delivery is used strategically to inform future policy decisions

- Influence the public imagination. Wherever possible aim to influence and shape the public debate and media narrative around cultural identity through these tools which have proven increasingly important in countering the negative discourse which many cultural communities experience

\section{Topp}

[/see_more] 


\title{
Economic Inclusion
}

\author{
By Mahmoud Bakkar
}

\section{By Amy Liu, Vice President and Director, Metropolitan Policy Program, Brookings Institution}

The geography of opportunity and poverty is shifting, creating a patchwork of concentrated advantage and disadvantage across cities, suburbs, and exurbs that challenges existing models of governance.

How can one create more inclusive economies in this disruptive age?

Cities are under pressure to deliver on a whole host of national priorities. In the U.S. that includes the nation's weak productivity growth, stagnant wages, and stark racial disparities. When an inclusive economy and a robust economic growth agenda is not a top priority for national governments, local governments, along with the private sector, are required to step up their investments in key domestic policy areas like infrastructure, job training, and housing_assistance.

As public and private sector leaders in metro areas set out to build more productive, inclusive economies, they should address the structural barriers, past and future, that prevent many people, places, and businesses from participating fully in the economy.

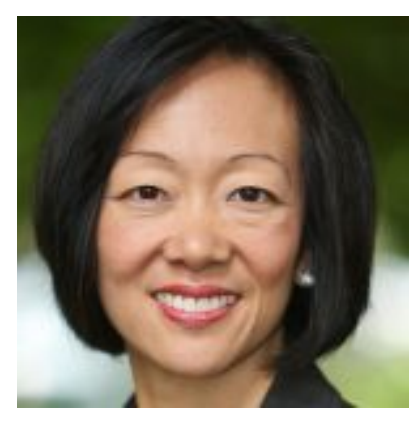

Amy Liu

Vice President and Director, Metropolitan Policy Program, Brookings Institution

At one level, this means that cities and metro areas must reverse the housing, land use, and infrastructure policies that have privileged white homeowners over black and brown Americans. At the same time, cities and metro areas must help their communities adapt to the rapidly shifting dynamics of the new era, which threaten to exacerbate inequality and exclusion. Technology is transforming every occupation and industry in cities large and small: According to forthcoming Brookings research, the share of U.S. jobs that require only low levels of digital literacy shrank from 56 percent in 2002 to less than 30 percent today. In just over a decade, the day-to-day duties of administrative assistants, toolmakers, truck mechanics, HR specialists, and numerous other occupations have dramatically digitalized.

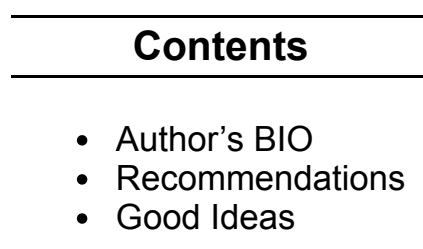

[see_more]

Additionally, the workforce that must be prepared for a digital economy is both aging and diversifying, with older, whiter generations and younger, multi-ethnic ones each seeking to navigate a changing labor market.

City and regional leaders can help their communities adapt in the following three ways:

Help people adapt their skills to the changing demands of our economy. Many older workers are struggling to translate their skills and experience into stable employment, while younger ones lack meaningful workplace experiences or personal networks to find good jobs. City leaders can help both groups by promoting apprenticeships and other workbased learning programs, organizing digital and global fluency_trainings, and ensuring work supports for near retirees. New York City, for instance, has launched Ladders for Leaders, a program that sets its sights on providing 100,000 jobs, internships, and mentorships per year for young New Yorkers by 2020 , particularly vulnerable youth.

Improve connectivity and access to better opportunities. Too many neighborhoods and jurisdictions within metro areas are isolated; cities can help re-connect them by investing in better transit, more affordable housing in opportunity-rich neighborhoods, and a network of innovation hubs and job centers across the metro area so that residents are close to jobs regardless of where they live.

Help businesses launch, scale, and innovate, promoting greater economic dynamism and productivity. Despite all of the promises of technological innovation, research confirms that business formation and productivity is flat, challenging workers' paths to upward mobility and income growth. City and metropolitan leaders can create healthier, more productive business ecosystems by helping firms invest in their employees and new digital solutions, encouraging entrepreneurship and start-ups, especially among underrepresented groups, and connecting small and mid-sized firms to new customers and markets abroad.

Achieving more productive, inclusive economic growth requires multidimensional action. Local and regional leaders will need to change mindsets, emphasize systemic reforms over narrow new programs, and reimagine ways to finance solutions. It certainly won't be easy. But in today's political climate, progress on these crucial objectives will increasingly depend on the adaptive actions of cities and metro areas. 
Editor's note: This post was originally published on the Brookings Metropolitan Policy Program blog.

\section{The Author}

Amy Liu is vice president and director of the Metropolitan Policy Program at Brookings, and the Adeline M. and Alfred I. Johnson Chair in Urban and Metropolitan Policy. She also directs the Global Cities Initiative: A Joint Project of Brookings and JPMorgan Chase, which aims to help leaders in U.S. metropolitan areas reorient their economies toward greater engagement in world markets. In 2016, Liu authored "Remaking_Economic Development: The Markets and Civics of Continuous Growth and Prosperity" in which she argues that city and metropolitan leaders must adopt a broader vision of economic development that can deliver economic growth, prosperity, and inclusion for all residents.

For Amy Liu's full Brookings bio, click here.

\section{Recommendations:}

- Help people adapt their skills to the changing demands of our economy by promoting apprenticeships and other work-based learning programs, organizing digital and global fluency trainings, and ensuring work supports for near retirees.

- Improve connectivity and access to better opportunities.

- Help businesses launch, scale, and innovate, promoting greater economic dynamism and productivity.

- Address the structural barriers, in areas like housing, land use and infrastructure policies, that prevent many people, places, and businesses from participating fully in the economy.

Topp

[/see_more] - 


\title{
Educational Inclusion
}

\author{
By Mahmoud Bakkar
}

\section{By Ulrich Kober, Program Director, Integration and Education, Bertelsmann Stiftung}

\section{Cities Make the Difference When It Comes to Inclusive Education for Migrants}

In most countries, children with a migrant background are at a disadvantage in the education system. Often absent during the pre-school years, and learning in a second language, they commonly lag behind their native-born counterparts academically and are more likely to leave school without a certificate. They face greater difficulties in securing a vocational training position, and are less likely to enroll at a university or find a job.

Cities in which these disadvantaged children and youth live have a stake in changing this state of affairs. This is not only a matter of educational justice, but of wellfounded self-interest. Indeed, the consequences of spotty inclusion are reason enough to prompt change: On the one hand, youth lacking participation opportunities in society are soon marginalized and less able to actively influence or contribute to their communities. On the other, cities that feature a sound education infrastructure with schools and good child care facilities offer an attractive location for young families -with or without a migrant background.

\section{Migrant educational disadvantage is a complex issue}

Migrant educational disadvantage is difficult to eradicate because it is a complex phenomenon. While poor language skills, lack of knowledge about local education systems and the absence of social networks are in part to blame, a weak socioeconomic background is the main driver of educational disadvantage across all groups. Thus children with a migrant background face a dual disadvantage since these young people are far more likely to grow up in families with low socioeconomic resources.

[see_more]

Education systems worldwide grapple with how to level the playing field by compensating for the socially disadvantaged environments of some students. All too often, however, good intentions fail. For example, educators often count on the active participation of parents in ensuring a child's educational success. And though many parents may want to contribute, parents with low socioeconomic resources often struggle to do so. Not immune to unconscious (or conscious) bias, teachers frequently expect less of children from socioeconomically weak households than they do from those with higher education or greater professional success.

\section{Strategies for inclusive education ...}

However, educational exclusion is not a fait accompli. Indeed, we now have a growing number of evidence-based practices demonstrating how to go about improving educational inclusion and achieving better outcomes for migrant students. The key to success includes comprehensive strategies that account for the entirety of a person's educational trajectory, from pre-school to post-secondary, and which strengthen the capacity of educational institutions to develop a learning culture in which all stakeholders can be more effective. Equally important here is the need for all relevant levels of government administration to support such strategies, ideally with the participation and community-level insights of civil society.

\section{1) ... consider the full trajectory of an educational path}

Getting a good start is important. The earlier language skills support begins and parents show interest and involvement in their children's education, the likelihood of educational success increases. Promising local programs that promote migrant parents' language and education skills can be found, for example, in Auckland where 'multicultural' playgroups help mothers and their children feel at home and 'school-ready, or in Frankfurt where migrant parents are encourages to participate in their children's pre-school language learning classes. The Stiftung Polytechnische Gesellschaft offers scholarships to the entire family as a passport to student success. Getting an early start with kindergarten and other preschool programs is an advantage, assuming the quality of care is good and children receive the proper support. Cities should give high priority to establishing high quality infrastructure for early-childhood education. 
But getting a good start is not everything. Promoting strong second-language acquisition from primary schools onwards is crucial. Achieving educational inclusion may also require specialized programs and services to help migrant youth prepare for entry and success in the mainstream school system and later to transition to higher education, vocational training and employment. In the area of refugee education, Munich's SchlaU-Schule offers a good example of how a learner-centred approach can tackle issues of social integration in the classroom as a pathway to educational success. This award-winning school is being replicated in other regions of Germany (e.g., the Walter Blüchert Foundation's "Angekommen" (Arrived) project carried out with the North Rhine-Westphalia Ministry of Education in the cities of Dortmund, Münster, Bielefeld, Essen and the district of Recklinghausen).

\section{2) ... strengthen childcare facilities and schools}

Educational inclusion cannot succeed without strong educational institutions. Kindergarten, primary, elementary and secondary schools require a suitable learning environment: conditions, culture, and capable educators equipped to manage the challenge of diversity.

\section{Conditions}

All-day learning facilities are an important element of an inclusive educational framework. Facilities of these kind, often colocated with local community centres, are already standard fare in some countries. In Toronto, for example, public schools, community programming and childcare centres often share the same facilities. In other countries, like Germany, they must be expanded. The seeds of future educational and training opportunities are planted at these early learning and afterschool programmes where children and youth can continue learning into the afternoon in a safe, well-supervised environment. Community-serving organizations such as music, cultural or sports associations can cooperate with schools in such community hubs to offer extracurricular programming and thus strengthen their network of activities and offerings with schools, students and families.

Urban areas where a high percentage of migrants and other socially disadvantaged groups are concentrated pose specific challenges to achieving educational inclusion. Educational institutions require additional support in such cases. Toronto, the world's most diverse city, uses a particularly effective instrument for determining this support, the Learning_Opportunity.

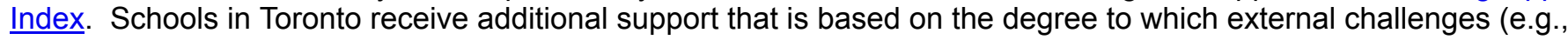
socioeconomic background) affect the success of their student population. These funds are used in part to finance measures like the "Inner City Model Schools" program that has supported schools located in communities in need for more than ten years.

\section{Culture}

Framework conditions are not everything, however. Open attitudes that appreciate diversity in education are also needed. For this purpose, mission statements are needed that hold up both excellence and equity as guiding principles for all actors to take seriously in ensuring fair and equal access to education opportunities. The Toronto District School Board stands out in this regard with its visionary statement on inclusion.

Learning cultures that are open to immigrant students demonstrate appreciation for these children's strengths and the things that make every child unique - that is, their family background and cultural roots. Within a culturally-sensitive learning environment, students can develop the self-esteem needed for successful learning processes to take place. Children who believe in themselves make for better learners. In Germany, some Länder like the state of Hesse are innovating around the handling religious differences: Schools in Hesse have begun integrating Islam into religious education curricula as a means of placing Islam on equal footing with Christianity from an educational and a social perspective. This demonstrates respect for the religious background of Muslim students that begins to shift the German narrative of identity and belonging. The Islamic faith, so often defamed in public discourse, is instead appreciated for its positive potential, and its adherents as equal citizens.

Self-esteem among migrant children can also be strengthened by incentives for social engagement when programs work with successful migrants as positive role models in integration.

\section{Capabilities}

The right frameworks and open learning cultures are important, but educators and related professionals must also be equipped with the appropriate skills. Good training is one of the most effective measures here. The QUIMS program in Zurich, which trains teachers in handling diversity, is a good example.

In response to the arrival in 2015 and 2016 of nearly 300,000 refugee children and youth in Germany, the Länder have launched a training campaign for teachers in the acquisition of German as a second language.

However, developing a positive approach to diversity and bilingualism among students should be more than a feature of teachers' continuingeducation: it must become a tenet of educator training in countries of immigration. 


\section{3) ... are accounted for across all levels of state administration}

Cities can be crucial in setting the course for expanded inclusion. But they cannot do it alone. Without the cooperation of federal offices and authorities, they will not surmount the challenge. A good example of this is presented by Canada's Settlement Workers in Schools (SWIS)_program, which is an expression of a partnership between local school authorities and Canada's immigration ministry. The program places social workers in schools with high immigrant numbers to help the new arrivals and their families integrate more easily. In Ontario, for example, some 200 Settlement Workers are active in more than 20 local schools. In Europe, funds for school social workers helping to facilitate inclusive education are drawn in part from federal sources. In Germany, Länder such as the state of North Rhine-Westphalia fund integration centers in cities that provide educational support for migrant families.

Inclusion can be achieved only if and when all levels of government administration - regardless of their particular competence and jurisdiction - work together across their silos in taking responsibility for the issue. A government-led community of accountable stakeholders of this nature could be open to the participation of civil society actors and charitable foundations vested in promoting migrant education. However, it must be absolutely clear that state actors bear ultimate responsibility for securing fair access to education opportunities.

\section{Educational inclusion pays off}

Educational success is not for nothing. But investing in good conditions and skilled actors pays off, as failed or interrupted paths to education incur high costs for communities and the state. The OECD has estimated that improved educational performance - measured in terms of increased PISA scores among students - would by 2090 massively increase the GDP of states with high migrant numbers. According to this estimate, Canada would gain an additional $\$ 3,743$ billion, the United States $\$ 40, \underline{647}$ and Germany $\$ 8, \underline{088 \text { billion. }}$.

\section{New ways forward}

However important good practices are, expanding educational inclusion to include migrants is not a "technical" challenge. Achieving inclusion is not primarily about implementing proven instruments or increasing budgets. Effective educational inclusion is an "adaptive" challenge for all stakeholders. Those involved on-the-ground make all the difference: they cannot simply return to whatever blueprints may be at hand - they must remain open to new modes of thinking and develop appropriate solutions for their cities. Parents, children, youth, educators, teachers, youth support professionals and those responsible for education issues at all levels of government will have to take new paths in order to expand and secure fair access to education opportunities.

\section{The Author}

Ulrich Kober is Program Director in the area of Integration and Education at the Bertelsmann Stiftung's headquarters in Germany. His current work and projects focus on triple win migration and global skill partnerships which benefits immigration countries, migrants and sending countries, European asylum policies and educational inclusion of disadvantaged students in Germany drawing upon international best practice.

\section{Recommendations:}

- Weak socioeconomic background is a major driver of educational disadvantage across all groups. However, conditions outside the classroom can be exacerbated in the classroom by unconscious bias and other forms of discrimination that adversely influence the learning environment.

- How can we improve educational inclusion and achieve better outcomes for migrant students? Develop comprehensive strategies that account for the entirety of a person's educational trajectory, from preschool to post-secondary, and which strengthen the capacity of educational institutions to develop a learning culture in which all stakeholders can be more effective.

- Getting an early start with kindergarten and other pre-school programs is an advantage when the quality of care is good and children receive the proper support. Cities should give high priority to establishing high quality infrastructure for early-childhood education.

- All-day learning facilities are an important element of an inclusive educational framework. Communitybased early learning and after-school programmes provide a safe, well-supervised environment where children, youth and their families can enjoy common ground for learning. 
- Developing a positive approach to diversity and bilingualism among students should be more than a feature of teachers' continuing education: it must become a tenet of educator training.

- Achieving inclusion is not a 'technical' challenge solved by implementing proven instruments or increasing budgets. Effective educational inclusion is an "adaptive" challenge for all stakeholders.

Top

[/see_more] 


\title{
Employment Inclusion
}

\author{
By Mahmoud Bakkar \\ May 17, 2017
}

\section{By Abigail Fulton, Executive Director, Construction Foundation of British Columbia}

\section{Employment is a Key Indicator of Economic Inclusion}

Economic inclusion refers to equality of opportunity for all members of society to participate in the economic life of their country as employers, entrepreneurs, or employees, as well as consumers. Employment is a key indicator of economic inclusion, and ultimately, long-term integration in an immigrant receiving society. Access to employment, adequate income and equitable employment opportunities are significant contributors that impact individuals' choice of where to live, go to school, and type of service they can access and enjoy.

Economic inclusion also fosters social integration between newcomers and local communities, helping to develop ties and connections between groups to bridge the gap of unfamiliarity of the foreign and local. More importantly, economic inclusion is a social determinant of health indicator, referring to the "economic and social and conditions that shape the health of individuals, communities and jurisdictions as a whole." The impact of inadequate employment opportunities and access to equitable income is beyond material deprivation and is linked to anxiety, depression, isolation etc. The disproportionate representation of immigrants and refugees in precarious work, unemployment and underemployment, puts them at a higher risk of suffering from these conditions, which have serious and negative consequences for their overall integration prospects.

[see_more]

\author{
Abigail Fulton \\ Executive Director, Construction \\ Foundation of BC
}

\section{$\overline{\text { Contents }}$}

- Author's BIO

- Recommendations

- Good Ideas

Economic inclusion is critical for successful integration. Ten years after arrival, integration success is often measured by attachment to the labour market. Immigrant unemployment and underemployment rates, credential and prior learning recognition, wages and salary earned, and the type of jobs available to immigrants are indicators used to determine economic inclusion and labour market integration.

\section{Employers and good corporate citizens}

Traditionally, immigrant and refugee settlement needs have been a responsibility of the receiving government and the associated institutions and organizations established to support newcomers' settlement, including employment. Employment needs and opportunities fell within the realm of government responsibility. But the narrative is changing, and the scope of responsibility is expanding to incorporate private sector employers as primary stakeholders in facilitating immigrant employment opportunities. As emerging leaders, employers represent global corporate citizens with the resources to invest in the inclusion and integration efforts of local immigrant and refugee populations. Whether as government allies, key stakeholders or motivated by business needs, private sector employers are taking a lead role in facilitating and creating employment opportunities and access to meaningful jobs.

\section{Case Study: Private Sector Leadership: British Columbia Construction Association}

Abigail Fulton, the former VP of the British Columbia Construction Association (BCCA) and current Executive Director of the Construction Foundation of $\mathrm{BC}(\underline{\mathrm{CFBC}})$, has focused on developing workforce solutions for the construction industry for twenty years, and immigrants have always been part of the solution. Finding innovative and workable solutions to filling the skills gap emerging within the construction sector due to increased economic activity and an aging workforce across Canada is her primary goal. Looking to newcomers to fill the skills gap and labour market shortage is more than just a workforce solution, it's active extension of Canada's immigration policy as a tool for nation building.

The construction workforce (in Canada) is comprised of $30 \%$ workers born abroad, and employers in the field are quick to welcome the skills and work ethic typical of new Canadians, quickly integrate them into the workplace and facilitate their upward mobility to secure and stable careers in the sector. Recognizing the fit between immigrant talent and employer demand, Abigail and her team developed employment programs (pre-arrival \& post-arrival) designed specifically to match new Canadians into the workforce, both before and after they landed in Canada. Assuming the lead role as connector between demand and supply, the BCCA and CFBC enable thousands of new Canadians to continue, or develop, their career path in British Columbia, while meaningfully contributing to the infrastructure of their new communities. 
For British Columbia employers, integrating and supporting newcomer populations is not just about meeting business needs, it's about investing in local communities and leading by example in developing the communities they want to live in.

\section{Why Hire?}

Labour market exclusion of immigrants has a significant impact on the economic stability of the communities and countries they live in. Despite high levels of education, internationally acquired experience and credentials, many immigrants experience poor labour market outcomes. As many struggle to find work opportunities commensurate with their skills, industries and sectors in many western nations are forecasting labour market and skills shortages in the next 10-20 years. Investing in immigrant and refugee talent and implementing organizational culture change today, will greatly differentiate between employers equipped to address these project challenges, and those that are not.

In Canada, it is estimated that 1 out of 13 workers earns a living in the construction industry, with a total workforce of over 1.3 million people. The industry has, and will very likely continue, to experience skills shortages across Canada, particularly in the skilled trades, based on projections for economic growth and the impact of retirements over the next decade. Across all industries and sectors there are challenges associated with hiring newcomer populations that range from cross-cultural communication, onboarding, language proficiency, and work culture familiarity; the challenges are most pronounced among small and medium sized enterprises (SMEs). Many SMEs do not have HR departments, have small teams with individuals assuming various functions and roles, and do not have the resources or time for training and development that is beyond what is required for the job.

Employment in the construction industry is spread out among many small and medium sized enterprises, with more than $80 \%$ of construction firms staffed by 10 people or less. With such limited resources, recruitment practices are generally limited to word of mouth and/or local advertising, and are often built on existing relationships and networks. Finding the company that is hiring and getting through the door to talk to the right person is not easy.

This is particularly challenging for immigrants, not yet familiar with their new communities and possibly struggling with language barriers. For the BCCA and CFBC the solution was to work with third-party organizations with industry expertise. Their role is to liaise between employer and newcomers; assess and match the skills of newcomers, and match them with existing employment opportunities.

Finding innovative solutions to language barriers are managed on worksites with the help of bilingual supervisors that can speak the official language (English or French) and native language of workers (i.e. Arabic for many Syrian refugees with limited English language proficiency).

The industry is very cyclical, experiencing times of quick growth and immediate needs followed by lay offs and project dormancy. Matching (job) opportunity to immigrant talent requires a good knowledge of local project activity and an understanding of the industry process. Recognizing that this is a challenge for many newcomers unfamiliar with construction activity in their region, innovative solutions are developed and implemented.

This challenge is manageable if that third party intermediary is tapped into industry in a meaningful way. In British Columbia it's the Skilled Trades Employment Program (STEP) at the BC Construction Association. STEP operates out of the various Construction Associations across BC enabling their staff to have direct knowledge of what is being built and by whom. Equipped with knowledgeable staff with firm backgrounds in the industry, they are able to quickly assess and match immigrants into the right job.

Demand for skilled trades workers is high, but developing those skills is not as simple as picking up the tools or even going to school. Like many professions, experience is required. To achieve a trade qualification and required certification, immigrant job seekers must first find employment with an employer who is willing to sponsor them into apprenticeship and contribute to their training on the worksite over several years. For immigrants with training qualification from their home countries, identifying the pathways to credential recognition, or maximizing and matching competencies to available opportunities can be very challenging. Finding an employer, especially a SME to "take a risk" and hire someone with internationally attained skills and experience, is an added layer of difficulty, and for many newcomers, is an impenetrable block to opportunities and careers.

However, all of these challenges must be overcome to enable the industry to meet its skills needs and contribute to the growth of our economy. In B.C. recognizing that young Canadians are not entering the trades at the rate needed to replace retiring workers fostered innovative and 'outside the box' thinking. For B.C. employers, the value of tapping into a talent pool that produces career oriented and long-term workers with a diversity of valuable existing skills is inextricably tied to the viability of the industry for generations to come.

\section{Cost of Exclusion}

Brain waste, the term often used to describe underutilization of immigrant skills and talent, carries long-term implications for immigrant integration; for the immigrant and receiving country. Excluding immigrants from adequate and compatible work opportunities imposes costs on the economy. Those working below their skill level and at lower wages generate lower 
level of output, consume less and spend less. Access to jobs commensurate to their skills that allow for the use of their full human capital impacts many determinants of health associated with integration: a sense of belonging, active participation in community life, and mental and physical health.

Abigail Fulton sees that construction is a global industry and an increasing number of multi-national firms are entering the Canadian market place. Large firms recruit for skills from across the world, bringing new methods and skills to the marketplace. Small to medium sized firms need access to these same skills to more easily tap into new and innovative construction methods. For BCCA, immigrants can bring those skills to construction firms in Canada and boost the bottom line for all.

Building the next generation of skilled workers in Canada is top of mind for the construction industry. Immigrants play a significant role in supporting that growth. Tomorrow's skilled trades workers must pass through an apprenticeship system where the majority of training happens on the worksite through the oversight and management of journeypersons. Ensuring we have enough journeypersons to manage that training process is critical. Skilled immigrants who bring skills from off shore that can be recognized by Apprenticeship Authorities in their region can boost the opportunities for small firms to take on new apprentices and help grow the workforce of tomorrow.

\section{The Author}

Abigail Fulton is Executive Director of the Construction Foundation of BC; and Vice President of the BC Construction Association. A lawyer by profession, Abigail works with industry and government on regulatory and policy issues impacting the construction industry. She currently leads the BCCA Foreign Skilled Worker BC initiative and works to bring in foreign trained, qualified trades people to BC, as well as the BCCA Integrating Newcomers Program that helps new immigrants find employment in BC prior to landing in Canada.

\section{Recommendations:}

- Demand driven immigration: align immigration to labour market need and information.

- Support Small and Medium Sized Enterprises (SMEs) connect to immigrant talent.

- Seek out third party "connectors" who know industry and sector needs and can assist in finding qualified immigrant job seekers, and support their on-boarding into the workplace.

- Collaboration between government, industry leaders, educators and immigrant serving agencies is critical to ensure opportunities are not missed to fully leverage immigrant talent in meeting the demands for continued economic growth

Top

[/see_more] 


\title{
Entrepreneurship Inclusion
}

\author{
By Mahmoud Bakkar
}

\section{By Jan Rath, Professor of Urban Sociology, Department of Sociology, University of Amsterdam}

\section{Entrepreneurship as a Key Component of Economic Inclusion}

The immigrant population in advanced economies has become more and more diverse in terms of ethnic or national origin, but also in terms of length of stay, educational achievement, and socioeconomic position. As for the latter, a substantial number of immigrants have set up businesses and become 'ethnic entrepreneurs'. The governments in many countries and cities expect or hope that this 'ethnic entrepreneurship' will contribute significantly to the integration of immigrants, their upward mobility, and the economic development of the city of residence.

Immigrant entrepreneurs can be important for various reasons: they create their own jobs; can create jobs for others; can develop different social networks than immigrant workers; and, last but not least, shape their own destinies rather than collecting welfare benefits and waiting for cues to become active. Also, they can provide a different range of goods and services; they can enhance the vitality of particular streets or neighbourhoods in cities or of specific economic sectors; they can give an added value to the appearance of the city. And of course they can play their part in the 'natural' process of succession and renewal of the total corpus of entrepreneurs.

[see_more]

Given the enormous variety of entrepreneurial trajectories, it is inappropriate to portray them one-dimensionally. Yet, in policy and academic speak this happens all the time. The ethnic character of the entrepreneur or the businesses is often taken for

\section{Jan Rath}

Professor of Urban Sociology, Department of Sociology, University of Amsterdam

granted and highlighted without further discussion as one such all-explaining

characteristic. However, the very fact that large and diverse groups of people engage

in entrepreneurship and that they do so in different locations and different sectors

makes it improbable 'that entrepreneurship can be explained solely by reference to a characteristic of certain people independent of the situation in which they find themselves'. Structural conditions are to be taken into account, including the policies and interventions that explicitly target ethnic entrepreneurs. In this essay, we draw attention to a host of governmental and non-governmental rules, regulations, measures, programs, schemes and policy actions that shape selfemployment trajectories in general and those of immigrants in particular. Do they help to promote the development of immigrant entrepreneurship?

Although there have been notably successful immigrant entrepreneurs, many seem to gravitate towards markets at the lower end. Lacking —often, but not always — access to significant funds of (financial) capital or appropriate educational qualifications, most fledgling immigrant entrepreneurs are active in markets with low barriers of entry in terms of capital outlays and required educational qualifications. In these markets, production is mainly small-scale, low in added value, and usually very labour intensive. Consequently, earnings are typically relatively low and days are long and hard. There are interesting indications, though, which entrepreneurs from the second generation of immigrants, who are often better educated than their parents, are able to position themselves in more profitable markets. However, the opportunities most (first-generation) immigrant entrepreneurs find in lower-end retailing, wholesaling, and restaurants and catering are closely linked to the vacancy chains where the most recent entrepreneurs replace earlier ones (ethnic and mainstream alike). Unfortunately, with relatively low entry barriers, these vacancy-chain markets are easily saturated. These conditions serve to squeeze profit margins and foster informal practices. Immigrant entrepreneurs, especially those who are risking unemployment or unattractive wage labor conditions, are pushed rather than pulled to these less-promising market segments.

But there is increasingly another kind of immigrant entrepreneur: this type tends to be highly educated and connected to different (more resourceful) social networks, and is better qualified to operate in post-industrial growth markets such as ICT, finance, insurance, real estate, media, tourism and entertainment. Entrepreneurs of this kind are pulled rather than pushed to these markets and, because of their higher levels of human and social capital, they seem to fit better the requirements of today's post-industrial economy.

This too illustrates that different markets offer different opportunities, put up different barriers, require different skills, competencies and resources (in terms of financial capital, social network, educational requirements and so on), lead to different forms and levels of success (however defined), and eventually a different division of entrepreneurial labour. Any 
attempt to promote immigrant entrepreneurship or, more generally, any interference in the market needs to take account of this dynamic multifacetedness.

This multifacetedness is not just the product of changing demographic or economic conditions, but also of regulation. Entrepreneurs are active in a market economy, and market economies-including the more liberal ones-are always regulated, albeit the form and level of regulation may vary. Regulation is contingent on prevailing economic citizenship regimes. These regimes might be contradictory and incomplete, and they stipulate under which conditions market exchange and price regulation take place. They also stipulate which goods and services and which actors are legitimate. Regulation encompasses both legislative and non-legislative forms and is, therefore, more than just state regulation. Indeed, a multitude of state and non-state agents play a role in regulation processes, such as local, national and international governmental agents, unions, quangos, non-profit organizations, voluntary associations, and individuals and their social networks. Regulation in the forms of repression, constraining or enabling is dynamic and subject to political influences. Deregulation or non-actions, to be sure, are also forms of regulation.

A study carried out under the aegis of the CLIP Network (Cities for Local Integration Policy), found first of all that promoting immigrant entrepreneurship is far from self-evident. In most cases, immigrant entrepreneurship did not play a major role in the overall strategy supporting the integration of immigrants. In fact, we found a marked tendency to stay away from economic issues. And for as far as immigrant entrepreneurship was actually promoted, it rarely if ever formed part of a bigger economic agenda.

Most interventions aimed at strengthening the professionalization of the entrepreneurs by_providing training and coaching, providing business accommodation or making soft loans available. Some aimed at removing regulatory barriers for small businesses (such as lowering license requirements). The study also showed, interestingly enough, that immigrant entrepreneurs tended to be reluctant to ask for support or apply for outside help. Also, it seemed that many were not aware of the availability of support schemes. At the same time, governmental and non-governmental agencies offering support services often found it hard to reach out to them. This discrepancy pointed to a serious lack of communication and raised questions as to the efficiency of the support services.

We found a number of interesting patterns. First, there was rarely if ever a 'natural problem owner' in this policy field. This study found that in some cases local authorities initiated interventions, in other cases, the national government took the lead, and in yet other cases governmental agencies or combinations of agencies at different scalar levels were the primary actors. Governments and civic society institutions operated at different, but interconnected scalar levels, and at face value one may conclude that this indicates complementarity. The absence of a 'guardian angel', however, does not seem to be favourable for immigrant entrepreneurs.

Secondly, since many countries had been witnessing a multicultural backlash, the topic of immigrant entrepreneurship had become politically even more sensitive. While the absence of group-specific policies was sometimes interpreted as ignorant, assimilationist or even racist, the presence of such measures was sometimes argued away as being biased towards soft multiculturalism. It is a fact that immigrant entrepreneurs-being first of all entrepreneurs—are affected by general policies too. But do immigrant entrepreneurs - or entrepreneurs from other disadvantaged social groups-really benefit from 'colour-blind' measures? Perhaps. But in many cases, this was assumed rather than proved.

Thirdly, and related to the previous point, policy makers were facing the question whether they should aim at the entrepreneurs themselves or at their opportunity structure. Do (fledgling) entrepreneurs have deficiencies (like language fluency.) that need to be compensated for by a variety of programs that aim at strengthening their entrepreneurial qualities? Or is the emergence or growth of businesses thwarted by an unfavourable opportunity structure, and should entrepreneurship then be promoted by removing barriers or by offering new economic opportunities? Most cities, for as far as they were addressed ethnic entrepreneurship, opted for measures that supposedly targeted barriers to immigrant entrepreneurial success.

How things turn out in practice depended on a number of factors, varying from the number of immigrants, their migration history and national assumptions about the process of integration to national welfare-state models and concomitant trajectories of economic incorporation, the bureaucratic culture, the political landscape and so on.

Among the conditions that contributed to differences were, first of all, the particular immigration history of the cities and countries involved. Most north-western European countries had experienced massive immigration in the period immediately after World War II and developed legal frameworks or welfare arrangements earlier than elsewhere in Europe. Southern European countries were countries of emigration in the early post-war period, and many of these emigrants moved as guest workers to north-western Europe. These countries had only recently experienced large-scale immigration themselves. In addition, they did not tend to have the same welfare systems or social policies as some of the north-western European countries. This held even more for most of the central and eastern European countries, which had only very recently become the destination of immigrants.

In some cases, the size of the immigrant population influenced the existence or absence of special policies promoting immigrant entrepreneurship; in New York, immigrant businesses are seen as the backbone of the urban economy. Few or no measures were found in countries with historically small immigrant populations; whereas countries with new and 
emerging immigrant populations like Finland are more proactive. In other instances, countries were more concerned with national or historical minorities than with freshly arrived immigrants. This was the case in some eastern and central European countries, where many recent immigrants were refugees.

A third condition pertained to the make-up of the welfare state and the concomitant employment and entrepreneurial trajectories in general and the economic citizenship regimes in particular. Whether or not self-employment is a 'natural' way to enjoy economic citizenship rights and whether or not the (local) state is to play a leading role is contingent on the type of welfare regime-liberal, corporatist, socio-democratic, familial and so on (Kloosterman, 2000).

As has been said, despite the fact that we hit upon all kinds of measures and interventions, the most striking finding was that active and explicit promotion of immigrant entrepreneurship was not commonplace. Especially group-specific interventions appeared to be thin on the ground. Whether this pointed to a lack of confidence in ethnic minorities' capability to become successful business persons or the opposite, namely that ethnic minorities are considered as being fully capable of joining the tiers of successful business persons without any support, is a matter of further exploration.

Notes

[1] Rath, J. \& A. Swagerman (2015) 'Promoting Ethnic Entrepreneurship in European Cities: Sometimes Ambitious, Mostly Absent, Rarely Addressing Structural Features', International Migration, 54 (1), February: 152-166.

\section{The Author}

Jan Rath is holding a Chair in Urban Sociology at the University of Amsterdam, and is Associated with the Center for Urban Studies (CUS) and the Institute for Migration and Ethnic Studies (IMES) in the same university, www.janrath.com.

\section{Recommendations:}

- Coming soon

-

Top

[/see_more] 


\title{
Financial Inclusion
}

\author{
By Mahmoud Bakkar \\ May 18, 2017
}

\section{By Omar Khan, Director, Runnymede}

\section{What is financial inclusion and why is it an important issue for immigrants?}

Omar Khan, Runnymede Trust, offers expert commentary and context for a selection of good practices on financial inclusion that illustrate some of the multiple and overlapping strategies being developed by innovative local and community leaders in cities across Canada, the U.S. and Europe.

Across cultures, ancient parables explain the importance of saving when times are good and borrowing when times are bad to minimize our individual and collective suffering. Of course, some people were better able to build up savings or to see their debts honoured. Today, financial products have become both more necessary and more complex. And yet, the situation for lower income groups and migrants is similar - they are no more likely to be financially included than their ancient counterparts. In modern societies, however, the importance of financial products and services means that people who cannot access them are also excluded from participating fully in economic and social institutions.

\section{The cost of financial exclusion}

Financial exclusion is here defined as poor access to affordable financial products and services, most notably banking, savings, credit, insurance and advice. This exclusion affects many aspects of an individual's life. For example, people who don't have a bank account might have difficulty accessing basic services such as heating, water and other utilities. Workers who are paid in cash are vulnerable to unscrupulous employers and to criminals who target these "walking ATMs." Further, the "unbanked" might be forced to rely on other parties - such as "payday" or predatory lenders that charge extortionate rates to cash cheques and provide other day-to-day financial services. Building credit ratings and savings become essentially unattainable goals. Two possible reasons explain financial exclusion. First, some groups are either more risky or less profitable for financial institutions; in other words, institutions believe it is more "costly" to design products for these people. Second, existing financial institutions are unable or unwilling to design new products and services for groups that don't fit into their existing practices.

[see_more]

This, then, suggests two strategies for responding to financial exclusion. The first is to accept or slightly adapt existing practices; the second is to design new institutions or ways of doing things so that everyone is financially included.

\section{Towards financial inclusion}

Real world interventions to ensure migrants are financially included now typically adopt both perspectives: working with existing institutions and practices and reforming them to include migrants, and at the same time developing new policies and practices. At the policy level, strategies include improving employment opportunities by adopting wide ranging or targeted education, and labour market policies that address for example, equality, discrimination or precarious work. Other interventions include ensuring access to affordable housing and healthcare.

In terms of practice, a common way of adapting is to provide financial education or financial literacy through which participants better understand ideas and concepts such as interest rates, insurance, mortgages and basic accounting. This is particularly common in development contexts, and for people who may have less experience of financial institutions and practices. Successful practices, such as microloans or participatory budgeting, are being adopted from these contexts and used in developed nations.

Basic Banking - Three examples of financial education are Durham's Latino Community Credit Union, Offenbach's Fit for Finance, and Capital Area Asset Builders (CAAB) in Washington, D.C. In each of these cases, the financial institution or intermediary organization provides further education and literacy on financial issues, with the expectation that more informed consumers will take up more affordable financial products, be less likely to get into debt, and be better able to plan for the future. 
Significantly, in each case migrants are provided more than information on how to navigate finance: in Durham, local residents can open a bank account in a credit union without immigration documents; in Offenbach, Germany, migrant participants (mainly Turkish and Russian) could meet with a mentor for financial advice; and in Washington, D.C., CAAB offers a matched savings scheme as well as money management and financial coaching services.

Other good practices focus on existing products, and particularly on basic banking (see Scotiabank's StartRight Program, Bank On San Francisco, and the U.K.'s basic bank account). Access to banking may be likened to a utility or even a "right" given the need for a transactional account to participate in any kind of economic activity. And because migrants may not have the official identity documents demanded by many banks, practices that focus on access to banking can have a great impact.

Matched savings - Individual development accounts (IDAs) and microfinance are arguably the two most prominent alternative products to improve financial inclusion. Matched savings deviate from mainstream savings products by offering a "match" for each dollar saved (say 1:1 or 4:1) rather than an interest rate. This idea was first promoted by Michael Sherraden (in Assets and the Poor, 1991) and piloted in the "American Dream Demonstration" in 1997 to enable "lowwealth families to save and enter the financial mainstream...build assets and reach life goals.... These savings can be used to buy a home, pay for post-secondary education, or start a small business."

Internationally, such matched savings schemes have been adopted in countries including the U.S. (see the CAAB), Uganda, China, Israel, Japan, Singapore, Kenya, Hungary and the United Kingdom. Typically, such schemes do not focus exclusively on immigrants, though some U.S. programs focus on groups experiencing significant wealth and savings gaps: Native Americans (see Washington University Native Assets project), Latinos and African Americans (see Closing the Racial Wealth Gap; also New America Foundation).

Home ownership - One of the major aims of IDAs is to build up savings for a deposit for home ownership. Those who build up savings, seek home ownership, and invest in their children through education and other skills are thereby choosing to settle in their country of residence; for migrants, savings and wealth accumulation may be viewed as an indicator of successful economic integration.

An example of how policy both adapts existing practice (in this case mortgages) but also invents new ideas is the development of services since the 1990s for those Muslims who interpret the Islamic prohibition on interest as rejecting the interest rates underpinning mainstream mortgages. U.S. financial institutions have since developed a variety of services in response; for example the Chicago Reserve Bank offers interest-free "loans" in the form of joint-owner partnerships or by charging lease fees instead of interest.

Access to credit - Microfinance was originally piloted in developing countries as an alternative to modern forms of credit that are rarely available outside major cities. In countries including the U.K. (Fair Finance), Canada (Immigrant Access $\underline{\text { Fund }}$ ), the the U.S. ( Philadelphia or San Francisco) and Germany (Evers and Jung) microfinance has targeted migrants as well, who may either be excluded from mainstream sources of credit or face extortionate interest rates (often above $200 \%$ annual percentage rate (APR) in the U.K.) due to their lack of credit history. Fair Finance is a good example of the approach: the organization is locally based in a part of London with a large number of migrants, and hires a significant number of people from the local area. This local intelligence ensures that Fair Finance understands why particular clients need money, and any support they need to repay the loan or grow their business. Wherever it's developed, microfinance is typically based on more face-to-face interactions between the microfinance institution and the debtor to ensure a lower interest rate than those calculated by statistical risk-scoring. Fair Finance founder Faisel Rahman says, "We are returning to old style banking - relationship lending - and putting humanity back in the lending process."

The Immigrant Access Fund (IAF) in Calgary takes a similar approach to loans that aim to prepare immigrants for employment. The IAF takes a holistic view of both the borrower and "employability." As a result, loans are used for a variety of expenses - from tuition and exam fees to transportation to general living expenses. Loans are based on trust and good character, with an eye towards the borrower's potential. According to Dianne Fehr, executive director of the program, "We lend to people not based on where they are today, but where we believe they will be in the future."

\section{A broader vision of financial inclusion}

We need to distinguish strategies that more or less accept or adapt existing financial institutions and practices from those that seek more wholesale reform or even new institutions and practices. Given the dominance of mainstream finance, the importance of banking for those seeking work beyond the limited opportunities in the cash economy, the need for everyone to build up savings and wealth to realize their life goals, and the wider social participatory effects of financial inclusion, practices must seek to engage mainstream institutions to do more for migrants and other disadvantaged groups.

On the other hand, if we frame these questions solely in terms of financial inclusion, we are vulnerable to existing institutions and practices declaring some customers or clients are too risky or costly to receive their services. As we have put it elsewhere "financial inclusion should be more expansively conceptualized to include economic well-being, personal autonomy and citizen participation." (Financial Inclusion and Ethnicity, 2008) 


\section{The Author}

Omar Khan is Director of Runnymede, UK's leading independent race equality think tank. Prior to this he was Runnymede's Head of Policy and led the financial inclusion programme. Omar is a Governor at the University of East London and a 2012 Clore Social Leadership Fellow. Omar's other advisory positions include chair of Olmec, chair of the Ethnicity Strand Advisory Group to Understanding Society, chair of the advisory group of the Centre on Dynamics of Ethnicity at the University of Manchester, Commissioner on the Financial Inclusion Commission and a member of the 2014 REF assessment, the 2011 Census, and the UK representative (2009-2013) on the European Commission's Socioeconomic network of experts.

Omar is the author of Financial Inclusion and Ethnicity; Caring and Earning_Among Low-income Caribbean, Pakistani and Somali People; Who Pays to Access Cash?; Why Do Assets Matter?; A Sense of Place; and The Costs of 'Returning' Home and numerous articles and reports on political theory and British political history. A highly regarded expert on issues of multiculturalism, integration, socio-economic disadvantage, and positive action, Omar has given evidence to the United Nations in Geneva, the European Parliament in Strasbourg, on Capitol Hill in Washington DC, among many other academic conferences and engagements in the UK and Europe.

For Omar Khan's full bio, click here.

\section{Recommendations}

\section{- Coming soon}

-

Top

[/see_more] 


\title{
Health Inclusion
}

\author{
By Mahmoud Bakkar \\ April 19, 2017
}

\section{By José Ramón Fernández-Peña, Associate Professor, Department of Health Education, San Francisco State University}

Immigrants in the United States often face difficulties gaining comparable employment held in their home countries. Despite substantial experience in their field, advanced degrees and credentialing, and a need for a diverse health field in the United States, many barriers keep educated immigrants under and unemployed. The Welcome Back Initiative (WBI) was established in San Francisco, CA to help address these difficulties. Since its inception in 2001, the Welcome Back Initiative's model of service has been adopted in 11 centers across 9 states in the United States.

Following with its mission statement to "Build a bridge between the need for more culturally and linguistically diverse health professionals and the untapped resource of immigrants trained in a field of health in another country who are now living in the US", the WBI aims to assist immigrants re-enter comparable positions held in their country of origin. This is accomplished through educational case managers providing participants with assistance in re-licensing, career options, knowledge of the U.S. health sector and necessary educational resources and support.

José Ramón Fernández-Peña Associate Professor, Department of Health Education, San Francisco State University

To address the growing diversity in culture and linguistics in the United States, the WBI aims to improve the diversity of the health work force to match the cultural and linguistic needs of an increasingly diverse U.S. population. To date, WBI centers has served over 15,000 participants from 167 different countries. The WBI has helped thousands of health professionals re-enter the health workforce. On average, participants in increasing their annual income by $255 \%$ from initial contact to the completion of their goals.

[see_more]

In Germany, Hannover's Ethno-Medizinisches Zentrum has developed the awardwinning MiMi programme that recruits, trains and supports individuals from within immigrant communities to become cultural mediators who can help navigate new and different ways of dealing with traditions of health and illness and the body. The goal of the program is to make the German health system more accessible to immigrants, increase their health literacy while simultaneously empowering immigrant communities by prompting their direct participation in the process.

In the UK, organizations like Maslaha are promoting health to Muslim communities with culturally sensitive resources and tools -and achieving health outcomes that have captured the attention of national health authorities.

\section{What works}

There are commonalities among programs that have successfully integrated immigrants into the health field. For example, Volunteering for Health, Heart and Work at the Elizabeth Knox Home and Hospital in Auckland, NZ gives immigrants the opportunity to volunteer in residential health for seniors and persons with disabilities. The program helps volunteers practice in their field of choice, helping them gain experience while improving their English and interview skills for gainful employment.

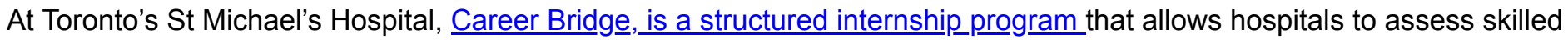
immigrants for permanent jobs. In Portugal, the classic case study is that of the Professional Integration of Immigrant Doctors programme(PIID) which helps internationally trained doctors (and nurses) navigate licensure processes while providing structured social support tailored to their needs. Why? To put their professional skills and cultural competencies to work for better services and health outcomes in the increasingly diverse population. This program saw much success, with over $90 \%$ of doctors in the pilot program began a career in medicine in Portugal. Like the WBI, these programs include elements of language skills, cross cultural communication, and literacy in the health field. All three programs build on the potential of their participants and focus on providing them with specific supports that will help match their skills and training to healthcare sector needs.

\section{Health inclusion requires a wide lens}


The best healthcare is preventative, and uses a "whole-of-community" approach. In Toronto, that includes hearing and vision clinics at school that ensure immigrant children in families not yet fluent in the official language don't get overlooked and left behind academically, as well as programmes that mediate culturally sensitive topics like sexual health. In Auckland, parents and students use a Walking Schoolbus to promote health and safety and foster a community of good neighbours. Access to sport and recreation, parks and green space are also important components of healthy living.

\section{What doesn't work}

While a growing number of programs are helping integrate immigrant professionals into the health workforce, many barriers remain. Limited funding is available for the costly licensure and re-training programs that specifically serve this population. Private funds are usually time-limited and public funds tend to have un-realistic goals given the complexity of the re-licensure processes and the myriad variables at play. Without dedicated staff and support, these programs end up being dismantled or integrated into other departments resulting in fragmented services and worse outcomes.

\section{Cost of Exclusion}

The under and unemployment of highly skilled immigrants is detrimental to the countries in which they reside. In the United States, a recent study conducted by the Migration Policy Institute finds that underemployment of immigrant college graduates results in tens of billions of dollars in forgone earnings and taxes annually, which in turn affects the economy at every level by lowering productivity and consumer demand. MPI estimates this is costing an average of 39.4 billion dollars per year in forgone wages and 10.2 billion dollars in forgone taxes.

Minority populations are severely underrepresented in the health field. In the United States, there are four times as many Hispanics in the general population than there are represented in the health field. According to the Sullivan Commission report, health professions have not kept pace with the diversity of societies. This contributes to more health disparities faced by minorities. For example, minorities are more likely to adhere to treatment when practitioners are of the same ethnicity. Another challenge in the U.S. is the shortage of health providers in lower-income and rural areas. Immigrant health professionals are more willing than their U.S.-trained counterparts to work in these underserved areas, yet they are not being utilized.

Underemployment also results in a lack of civic integration. Immigrants employed in the field in which they were educated are more likely to contribute to their families and their communities.

Immigrants also face many exclusionary, protectionist policies in certain countries. These ill -guided policies make it almost impossible to enter the workforce. While it is imperative to ensure that health professionals are well prepared to do their job, some of these policies seem to be more concerned with protecting the professional associations' financial interest than the public's safety.

In sum, to successfully incorporate immigrant health professionals into their new countries, policies are needed to support health professionals in the recognition of their licenses from other countries. For example, the Bologna Process was created to insure a standard of higher education in 48 different European nations making degrees more compatible. It aims to create greater mobility and employability among college-trained workers. The Professionals Access to Healthcare (PATH) Act is a proposed bill in the United States that would ease the transition for internationally trained professionals to work in healthcare under the Health Equity and Accountability Act.

\section{The Author}

José Ramón Fernández-Peña, MD, MPA - is an Associate Professor and the Associate Chair of the Department of Health Education at San Francisco State University where his works focuses on health workforce diversity and cross cultural communication in health. He is the founder and director of the Welcome Back Initiative (WBI), a program to assist immigrant health professionals already living in the U.S. through the necessary steps to enter the U.S. health workforce. The WBI currently includes centers in California, Massachusetts, Rhode Island, Washington, Maryland, New York, Colorado, Pennsylvania, and Maryland. In 2010, the program was recognized by the Maytree Foundation as one of the world's 15 most successful programs for immigrant integration. In 2011, it received the E Pluribus Unum prize from the Migration Policy Institute. The program has served more than 15,000 people from 170 countries and has assisted thousands in joining the US health workforce.

He received the "Champion of Health Professions Diversity" award from The California Wellness Foundation in 2011. Also, in 2011, he was recognized by the White House as a "Champion of Change" for his work on immigrant integration. In 2012, he received the Henry J Montes President's Award from the American Public Health Association (APHA) Latino Caucus for his work with the Latino community. 


\section{Recommendations:}

In sum, to successfully incorporate immigrant health professionals into their new countries, several factors have been shown to assist in the process:

- Individualized guidance and support that includes a full exploration of the challenges and opportunities for licensure is essential.

- Contextualized language acquisition programs are a critical service needed for success.

- Building a sense of community promotes positive outcomes for immigrants, therefore, efforts to expand social and professional networks among health professionals will help contribute to a better transition.

Top

[/see_more] 


\title{
Political Inclusion
}

\author{
By Mahmoud Bakkar
}

\section{By Sayu Bhojwani, Founder and President, The New American Leaders Project}

\section{Making Democracy Work for All: Political Inclusion as a Strategy for Integration}

Political inclusion measures the extent to which all members of a society are able to access the institutions of democracy. For immigrants and minorities, this access allows us to be seen, be heard and be counted. It's critical to distinguish between individual access and group access, specifically as it relates to immigrants and other minority groups. For example, if one individual from these groups, by virtue of their social or economic standing, are able to vote, run for office, or participate in civic leadership, we can't assume that a society is politically inclusive. A more accurate measure of political inclusion is the ability of any individual - regardless of their socioeconomic background or ethnicity - to access the levers of political power. The difference between one and any defines the scope of work ahead of us for political inclusion.

\section{Sayu Bhojwani}

Founder and President, The New

American Leaders Project

\section{Analysis}

What are the levers of political power that we need to ensure anyone can access? For the purposes of this exercise, let's look specifically at the ability and opportunity to vote, to be represented in government, and to have voice in policymaking. These forms of inclusion allow us to be counted, be seen and be heard. While voting is often restricted to those citizens with particular legal status, being represented by someone we identify with or being able to voice our concerns to policymakers is possible regardless of legal status.

\begin{tabular}{ll}
\hline Contents \\
\hline - Author's BIO \\
- Recommendations \\
- Good Ideas
\end{tabular}

[see_more]

\section{Voting for All}

Partnership for Immigrant Leadership and Action. In California, the state which attracts the most immigrants to the United States, Mobilize Immigrant Vote "successfully supported and connected the efforts of 112 organizations working in 15 diverse ethnic communities, in 17 California counties in order to increase the civic participation of immigrant groups and bring them together around their shared issues and concerns."

Count us In! was launched in 2011 by the Immigrant Council of Ireland "to raise awareness among naturalized citizens of their right to vote in the 2011 General Election, remind political parties and candidates of the need to engage with naturalized citizens and with the issues pertaining to immigration and integration, and remind politicians and canvassers that the electorate in Ireland was diverse.

\section{Representation for All}

Advocacy for the under-represented can raise awareness and organize collective action, but the route to elected office and the corridors of power requires sustained effort and technical know-how. Cities like Dortmund and Nashville recognize that its in their interest to actively recruit and train citizens for public office. In cities like Hamburg, the municipality hosts naturalization campaigns to ensure its promote the benefits of citizenship. The mayor sends every new citizen a personal letter of recognition.

Chicago's Voting Rights Act of 2011 makes progress toward reflective representation for the city's changing demographics. The act mandates that district lines for Congressional and state seats are drawn in ways that allow immigrants and people of colour to influence who represents them.

Who represents us matters, as researchers in Berlin have shown by assessing the impact of diversity in city councils in Germany. Their study found that no German city had proportionate representation of immigrants on its council, but recognized steady growth in the number of immigrant council members around the country.

\section{Voices of All}

All Parisians, All Citizens. In Paris, France, city government has created a venue for non-citizens to express their concerns about policy. This advisory council, created by Paris Mayor Betrand Delanoë in the early 2000s, allows non-European 
Union citizens, a platform from which to engage with the city's municipal leaders.

OXLO, Oslo Extra Large is a response by the municipality of Oslo to be more intentional about inclusion and diversity. In 2005, Oslo implemented "city-wide measures to increase cultural diversity through active city governance, such as addressing city government hiring criteria, emphasizing political participation through active citizenship and supporting increased co-operation among agencies, local government and other service providers."

In the United States and elsewhere, at a time when the idea of an inclusive society is under threat from federal policy and xenophobic activities, cities have asserted their determination to protect the rights of all residents. Mayors in the United States established Cities for Citizenship, to encourage eligible residents to naturalize. And municipal leaders have established "sanctuary cities", to serve and protect every resident in spite of exclusionary federal and state policies. Youth and adults affected by the termination of the DACA (Deferred Action Against Childhood Arrivals) program have seen an outpouring of support from municipal leaders determined to protect them and push Congress to pass legislation that will address the country's broken immigration system. These expressions of political power signal a shift in the parameters of municipal power and authority.

\section{Cost of Exclusion}

Our democracy is stronger when everyone participates. Lower levels of participation and representation weaken our democratic institutions, preserving power in the hands of a few - leaders, voters, and donors. These political elites then shape policy in their interests, rather than in the interests of the majority. When a society is diverse, in ethnicity, in occupational status, in gender and sexual orientation, its leaders need to reflect those diverse perspectives. This representation is not simply "for show." To cast our votes, to speak our minds, and to hear our experiences reflected in policy contribute to our sense of inclusion, our ability to participate, our access to power. If we don't feel our participation is welcome or possible, we feel marginalized and silenced. In the short-term, that can contribute to isolation and misunderstanding. In the long-term, it can contribute to racial tension and civil unrest.

\section{Being Reflective and Accountable}

The challenge of integrating diverse populations into democracies often designed to serve the wealthy and privileged few might seem daunting. But at its core, political integration is rooted in three values - authenticity, inclusion and accountability. Specifically, policymakers can ensure that these values are embedded into democratic institutions by doing the following:

Evaluating and re-evaluating regularly. With increasing migration and constantly changing demographics, policy and practice that worked a decade ago may not be adequate today. Staying in touch with how a community looks, lives and works requires constant and consistent engagement.

Going beyond diversity and representation to inclusion and equity. Practically, this requires diligent attention to who holds decision-making authority and power. Populating advisory committees with one or two migrants, for example, might check the box on diversity but unless the committee has influence and the members have voting power, we are not advancing political inclusion.

Mechanisms for accountability. How we hold our leaders and our institutions accountable determines how well they serve us. These mechanisms can include voting, but can also include community hearings, town halls, transparency around council meetings. Along with these, particularly for newcomers, we must ensure ways that residents are informed and included.

When decision-making centers these practices above individual ambitions or short-term gains, the results can be farreaching, creating the inclusive democracies that we all aspire to.

\section{The Author}

Sayu Bhojwani is Founder and President, The New American Leaders Project which she founded in 2010. She served as New York City's first Commissioner of Immigrant Affairs and is the founder of South Asian Youth Action, a communitybased organization in Queens. Her work to build a more inclusive democracy has been featured in The Wall Street Journal and in The New York Times. Her TED talk, "Immigrant voices make democracy stronger" has been viewed over 770,000 times. She is a 2017 Woodrow Wilson Visiting Fellow, a Visiting Scholar at the Eagleton Institute of Politics at Rutgers University and was named to the 2017 New Profit Accelerator cohort. Ms. Bhojwani earned a Ph.D in Politics and Education from Columbia University, where her research focused on immigrant political participation. She lives in New York City with her husband and daughter. @SayuBhojwani 


\section{Recommendations for Policy Makers}

At its core, political integration is rooted in three values - authenticity, inclusion and accountability.

Policymakers can ensure that these values are embedded into democratic institutions by doing the following:

- Evaluating and re-evaluating regularly. Staying in touch with how a community looks, lives and works requires constant and consistent engagement.

- Going beyond diversity and representation to inclusion and equity. Practically, this requires diligent attention to who holds decision-making authority and power. Populating advisory committees with one or two migrants, for example, might check the box on diversity but unless the committee has influence and the members have voting power, we are not advancing political inclusion.

- Mechanisms for accountability. How we hold our leaders and our institutions accountable determines how well they serve us. These mechanisms can include voting, but can also include community hearings, town halls, transparency around council meetings. Along with these, particularly for newcomers, we must ensure ways that residents are informed and included.

Top

[/see_more] 


\title{
Role of Media
}

\author{
By Mahmoud Bakkar
}

By Rob Berkeley MBE, BBC Project Lead, Audience Accountability

\section{Staying 'Woke': How Diversity and Inclusion Will Save Public Service Media}

In June 2017, the Oxford English Dictionary extended their entry for the word 'woke'. They argued,

"The original meaning of adjectival woke (and earlier woke up) was simply 'awake', but by the mid-20th century, woke had been extended figuratively to refer to being 'aware' or 'well informed' in a political or cultural sense."

The Oxford lexicographers remain assiduous in their ongoing work to map the English language. More than the latest foray in the seemingly never-ending drive for dictionary sales, the evolving definition of 'woke' has some lessons for us in thinking about inclusion and diversity in public service media. The lexicographers go on to say,

\author{
Rob Berkeley MBE \\ BBC Project Lead, Audience \\ Accountability
}

"In the past decade, that meaning has been catapulted into mainstream use with a particular nuance of 'alert to racial or social discrimination and injustice', popularized through the lyrics of the 2008 song Master Teacher by Erykah Badu, in which the words 'I stay woke' serve as a refrain, and more recently through its association with the Black Lives Matter movement, especially on social media."

Language changes. Change is key in enabling us to describe our world in a fresh manner and share our insights with each other. Any user of the language can trigger its development without the need for external validation or official diktat. However when the meaning of a word changes for some but not others, this can put at risk the ability to communicate between groups. The lexicographer performs a crucial (and powerful) role in enabling developments in language use to be captured, codified, analysed and shared. A task transformed by the growth in publicly available data about the ways in which we use language through social media. In the case of the extended meaning of 'woke', it took those lexicographers nearly ten years to notice, respond and amend the dictionary accordingly.

[see_more]

The BBC has recently renewed its royal charter; a process that involved a broad public debate about what the next ten years holds for the BBC. The debate reflected widespread agreement that given the speed of change in both the make-up of British society and the media landscape, the BBC does not have the luxury of the lexicographers' ten years in which to work out its responses. Individuals have always sought to use the media, like language, creatively, and as the barriers fall to creating media content (and to distributing it solely among discrete groups of people similar to us (1) ), our options for self-expression grow. One of the outcomes of the greater choice of content and means of receiving that content, is the potential reduction in shared experiences; the end of the 'water-cooler' moment at the more trivial level, but also a threat to a public sphere that is inclusive and diverse, and public debate that is informed by all who have a stake in it.

There are competing visions of what the public sphere is and how it is constituted. For some the public sphere exists as a neutral space where the public meet to inform each other, and engage in debate so that the citizen can then make informed decisions (2). Others would question whether there can ever be a neutral space of this kind; immune to structures of exclusion on the basis of wealth or identity. They suggest instead that we have a series of overlapping publics and counter-publics - some with more access to power and resources than others(3). Which you believe to be the more accurate description of the media landscape has a significant impact on what you do as an organization seeking to inform, educate, and entertain the diverse peoples of a diverse nation. Whatever your conception of the public sphere, however, it is clear that the lessons from 'woke' apply here - media forms are dynamic and changing at pace; people will create their own forms of media without the need for official approval; there is a role for media which operates in the public interest to reflect and capture changes in that expression; and that role is a powerful one which is likely to become more rather than less significant as media sources and platforms proliferate.

The most direct way to respond in this context is to have voices and experiences from right across society. within the organization, learning from each other and collaborating to create relevant content. This is why the BBC has set stretching targets for the diversity of its staff, with progress reported publicly by by grade and by_protected characteristic. It also takes its 
responsibility to the industry seriously, using its buying_power to encourage greater diversity, creating media centres and hubs across the nations and regions, working alongside industry partners, and building the diverse workforce of the future through an emphasis on apprenticeships , as well as supporting media and technology education (including the MicroBit and $\underline{\text { School Report). }}$.

\section{Listen better}

The second part of the response is to listen better. More people should get the opportunity to have their say on the content and feel that they can influence an organization that is both responsive and accountable. Beyond the formal complaints processes, online personalization will provide much more accurate data on audience views. Initiatives like BBC Three Playground, and BBC Children's Stepping Out, BBC Scotland's The Social, or Radio 1 Youth Council bring audience insights direct to the decision-makers commissioners.

A further response to the new media challenge to the public sphere is emerging in the way that the BBC responds to its mission. With television sets and radios potentially going the way of the typewriter, telephone landline and video recorder, there has been a revolution in media consumption patterns. Online on-demand services account for over a third of TV viewing hours in the US. Increasing numbers of people no longer own a television. Immersive virtual reality is already here and the technology is moving at pace. A report from the British media regulator, Ofcom, noted that:

Viewing of broadcast TV by children (four to 15 years old) and 16- to 24-year-olds fell 33\% between 2010 and last year .. . At 344 minutes viewing per day on average, pensioners clock up more than triple the amount of traditional TV viewing of children and younger viewers.

This month, the BBC published its first Annual Plan under its new charter . In the Annual Plan the organization takes the opportunity to set out its creative vision for the year ahead. It is clear that among commissioners there is a desire to create content that brings people together in both reflecting and defining a diverse nation.

Drama. A strong streak of Britishness must run through the centre of everything we do... So our plan is for the next five years of drama from the BBC to be a celebration of British authorship, identity and life in all its most diverse forms.

Entertainment. Entertainment unites audiences through uplifting and inspirational content. In a world of change and uncertainty, the UK needs feel-good, innovative entertainment shows more than ever. Entertainment brings big broad audiences together, fuels the national conversation and reflects the diversity of the UK. In a world where audience viewing is increasingly fragmenting, entertainment shows provide big appointment-to-view events and talked-about shared viewing moments.

Comedy. The BBC's creative mission in comedy is simple - we should make people laugh. But comedy from the BBC also helps define and reflect our diverse national character

Sport. The BBC's aim in sport is to bring audiences the big sporting moments that unite the nation

Nations and Regions. Our programmes need to be made across the UK's Nations and regions. Our local and Nations services need to be relevant to audiences in each place. But as well as showing what makes us different, we must also celebrate what brings us together for shared experiences and the national conversation.

Being able to host a 'national conversation' requires the ability to know and understand that nation (and know who is not being included), to be able to bring people together around shared concerns, and to have them want to come back. The BBC has put diversity and inclusion at the forefront of its efforts in this arena. Without a prioritisation of activity that creates a more inclusive organization, that develops trust among a diverse range of audiences, and unifying shared experiences that are inclusive and attractive, public service media may struggle to maintain its foothold in an increasingly crowded and contested public sphere.

Today, the BBC's role to reflect all the communities of the UK has perhaps never been more important. Never has the pace of change in British life been so quick, and never has it been so vital that all of the country's voices are heard. We believe we are on the right track, but we are not complacent. We know we have to continue to work.

A period of anticipated constitutional upheaval, and a series of tragedies and atrocities that have hit British cities in recent months show how important an inclusive national conversation can be and how crucial it is that in that conversation, all voices can be heard, information is accurate, and that truth is spoken to power in the interests of the public. A failure to stay woke, to ensure that the BBC has access to insights and talent from all parts of Britain's diverse population, risks both the public sphere and the quality of public debate/democracy. Current key risks to informed and meaningful debate as a means of bringing society together is arise from a failure to include all but also from greater distrust in media sources.

At the end of June 2017 two new definitions were added to the Oxford English Dictionary; one was 'woke', the other, 'posttruth'. 
1. Pariser, Eli (2011) The Filter Bubble: How the New Personalized Web Is Changing What We Read and How We Think

2. Habermas, Jurgen (1962) The Structural Transformation of the Public Sphere: An Inquiry into a Category of Bourgeois Society

3. Fraser, Nancy. 1990. "Rethinking the Public Sphere: A Contribution to the Critique of Actually Existing Democracy." Social Text 25/26:56-80

\section{The Author}

Dr Rob Berkeley MBE. Award-winning busybody, recovering academic and reformed social reformer, Rob Berkeley currently plies his trade advising the BBC on accountability. Impatient with injustice and exasperated by wasted potential, he volunteers on the boards of Baring Foundation, and Britdoc Foundation, has previously served on the boards of Stonewall, Equality and Diversity Forum and the Oxford Access Scheme, and been Chair of Naz Project (NPL) and BGMAG. He was Director of the Runnymede Trust 2009-14. Alongside his academic writing on education, social justice and community organizing, he has presented and co-produced short form documentaries, and written for The Guardian and The Independent on racial justice. His current obsession with innovations in media technology and their potential for social justice means that he watches a lot of TV/film and calls it 'research'. Dr Berkeley was awarded an MBE in 2015 for services to equality.

\section{Recommendations:}

- Coming soon.

- Coming soon.

- Coming soon.

- Coming soon.

Top

[/see_more] 


\title{
Social Inclusion
}

\author{
By Mahmoud Bakkar
}

By Ratna Omidvar, C.M., O. Ont., Senator for Ontario, The Senate of Canada

\section{Living Together: Place-Based Social Inclusion}

Jane Jacobs has famously said in The Death and Life of Great American Cities:

"Cities have the capability of providing something for everybody, only because, and only when, they are created by everybody."

This in its essence is a living definition of place-based social inclusion. Inclusion is a powerful word, technically it includes all of us, old and young, new or not, rich and poor. But if there is one force over others that is driving the discussion around inclusion, then that force is migration and the resulting diversity explosion.

Ask any aspiring immigrant - where do you want to go? And nine times out of ten the answer will likely be New York, Vancouver, London, Berlin, and Singapore. Big cities, bright lights, opportunity, anonymity - these are the pull factors that combine with other trends in urbanization like density and clustering that make cities where the real noise and music of diversity is heard loudest. It is in cities that the new middle class is created, lifting people out of poverty into prosperity

Migration, and the resultant diversity is one of the most contested forces in the world. It is shaping our national and global policies in different ways, it bears the brunt of populism and has given rise to a particularly noxious kind of xenophobia. Yet, it is also the source of needed talent and workers, the only way to prop up aging populations in many parts of the western world, a rich source for innovation and cultural evolution, indeed some say for the progress of human kind. And whilst these discussions take place at global and national levels, their lived and most visceral

\section{Ratna Omidvar}

C.M., O.Ont., Senator for Ontario, The Senate of Canada

\begin{tabular}{ll}
\hline Contents \\
\hline - Author's BIO \\
- Recommendations \\
- Good Ideas
\end{tabular}
expression is found in cities. Therefore the capacity of cities to experiment and find, test and amplify solutions to inclusion are all the more important. At the same time, it also worth noting that cities also bear the brunt in the first line when exclusion prevails.

[see_more]

So let me make a few central observations about migration and diversity. The first is that whilst migration is a uniquely national and regional experience - people migrating from China to the USA or from India to Australia - their experience of inclusion or exclusion will be a uniquely local one. They will move in reality from Beijing to Chicago or from Bangalore to Adelaide. Their first and sometimes lasting experience of inclusion will be in your city schools, city buses and city libraries.

My second observation is that diversity and inclusion are not the same. One is a demographic reality, the other is a process that leads to equity and equality of opportunity, regardless of when and where you came from. Diversity is a demographic accident, inclusion is what you do with it.

My third observation is that inclusion does not happen accidentally, it takes intention, it takes resolution, and it takes leadership. Leadership to realize that a city that works for everyone must include everyone.

An inclusive city is much more than a prosperous city, because prosperity is not necessarily inclusive. An inclusive city is a peaceful city, a city of law and order. An inclusive city is a place where people feel safe, feel included, and know that their voice is heard, that their needs are reflected back to them in the shape of city policies and practices. So whilst these benefits may be more intangible to express, it can be argued that these are the most important reasons for city leaders to pay attention to deliberate targeted and preventative strategies and approaches to inclusion.

Let me start with a story from my beloved Toronto. One of the most if not the most diverse cities in the world. Also a city with fairly strict zoning by laws, which sometimes get in the way of place-making that is inclusive. But Toronto has overcome its fear of the unknown so to say, has adjusted bylaws at the behest of residents and as just one example, allowed for the building of open air ovens in the parks. Now in the summer, along with playgrounds and wading pools for children in Thorncliffe Park, there is an oven, which draws women, many of whom are isolated, who come out and bake naan and pizza, exchange tips and build community, because we all know that regardless of where we come from, the baking of bread is a communal event. 
Let's fly next to London, one of the most expensive cities in the world, with a very high cost of living. Both Mayor Boris Johnson and Mayor Sadiq Khan are champions of a local living wage, the LLW, which is pitched to the real cost of living in London and is higher than the national minimum wage. They exercise their leadership muscle not only in terms of their own as employers of a large work force in London, but also in encouraging employers to opt in.

Next to Copenhagen where more than $80 \%$ of the residents bike to work, the local government in partnership with the Red Cross, teaches migrant women not only to bike so that they can get to work or to shop or to classes, but also to understand traffic signals, to repair their bikes, and to decode written and unwritten rules of the cycling culture so that they become part and parcel of the fabric of the city.

The former Mayor of New Haven Connecticut, John DeStefano Jr., deserves special credit for his courageous yet very practical launch of a municipal identity card for all residents of the city, whether they are legal or undocumented. The care was designed as a protection for undocumented immigrants in New Haven. It was not only an identity card, but a library card, and a debit card to carry up to $\$ 150$. Today, sensible cities like New York, Chicago, Detroit, San Francisco and many others are in the process of doing the same.

Several cities have tackled misinformation and stereotypes: In Erlangen, Germany an engineering multinational has piloted a training program for asylum seekers as part of a city-led campaign to counter misconceptions about refugees. Barcelona has launched an anti-rumour campaign about immigrants overusing the social systems in the city. Dublin has launched an anti-racism campaign on public transport.

An idea from a city filling traditionally national space comes from Hamburg: The mayor of Hamburg sends personal letters of welcome to those immigrants who are ready to be citizens. Mayor Olaf Scholz saw the local benefits when Hamburg residents belong and have a stake in society. This tells us that all cities have a stake in citizenship uptake.

I want to end this tour of good ideas with the city of Montreal with an idea that is somewhat out of the box with these others that I have noted. It is so because it is courageous. The Mayor of Montreal, our host Mayor Dennis Coderre was once Minister of Immigration. He knows that inclusion also means bringing back people into the fold who have chosen the path of exclusion, who for some reason or other have not only no share in our society, but are determined to harm it. In 2015, he launched the country's first de-radicalization center. The centre helps families who are worried their children or relatives may be turning towards extremism. A 24-hour hotline is available for anyone with questions and concerns. It also refers calls to the police if they are deemed alarming enough. This intervention is immediate, it is local, it is accessible.

My first good idea is about thinking of public space and allowing yourself to reimagine it through the lens of inclusion. Public space matters. We often ignore the spatial dimensions of inclusion, the power of zoning as a means to bring people together, whether it is to celebrate, dance or protest. Think or repositioning space for new uses - such as deploying containers as startups for culinary entrepreneurship or the use of local swimming pools as places where inner city kids can fish.

My second good idea is about municipal policies. When these policies are deliberately inclusive, their impact is different and preventative. So think about your procurement policies, think about the hiring approaches. It's not just who you are, but who you hire and who you do business with. And perhaps think about a local living wage.

My third good idea is to encourage you to think about local initiatives to address and ease national pain, whether it is climate change or disease, but then ramp it up on the national stage. Vancouver is the first city that has taken a deliberate approach to closing the emotion, spatial, cultural and economic gap between the only two segments of our population that are growing - Canada's immigrants and Canada's Indigenous Peoples. If we are to be a reconciling nation, that reconciliation between these two communities is best started in our cities.

My fourth good idea is that a rising tide will lift all boats. Inclusion done well results in shared prosperity. This is true in economic terms, and in social terms as we know that cohesion and trust bloom in diverse, inclusive neighbourhoods. It is also true that inclusion for one group for newcomers strengthens your muscles for all others. This is a lesson from the gender equity movement.

My fifth good idea, and possibly my most important one is about mayoral leadership. When Mayor Emanuel of Chicago stands up for Sanctuary Cities, it matters. When Mayor Mueller of Berlin says that welcoming 70,000 migrants is no burden for the city, it matters. When Mayor John Tory of Toronto says that he will assess his presence at tech events against a diversity criteria, this matters too.

When mayors make social inclusion their business, then the magic of social inclusion gets a lift.

\section{The Author}


The Honourable Ratna Omidvar, C.M., O.Ont., is Senator for Ontario, The Senate of Canada. Senator Omidvar is the founding Executive Director and currently a Distinguished Visiting Professor at the Global Diversity Exchange (GDX), Ted Rogers School of Management, Ryerson University. GDX is a think-and-do tank on diversity, migration and inclusion that connects local experience and ideas with global networks. It is dedicated to building a community of international leaders who see prosperity in migration. Previously, Senator Omidvar was the President of Maytree, where she played a lead role in local, national and international efforts to promote the integration of immigrants.

Senator Omidvar is the current Co-Chair of the Global Future Council on Migration hosted by the World Economic Forum and serves as a Councillor on the World Refugee Council. She is also a director at the Environics Institute, and Samara Canada and is the Toronto Region Immigrant Employment Council's Chair Emerita and was formerly the Chair of Lifeline Syria.

For Ratna Omidvar's full biography, click here.

\section{Recommendations:}

- Coming soon

Top

[/see_more] 


\title{
Spatial Inclusion
}

\author{
By Mahmoud Bakkar
}

\section{By Myer Siemiatycki, Professor of Politics and Public Administration, Ryerson University}

Migration and urbanization are twin drivers of global change today. Depending on how cities respond, we could be headed for hard times or a golden age ahead. The good news is we now have ample 'best practice' evidence of how to arrive at a happy ending.

\section{Cities of Exclusion or Inclusion?}

In this age of migration, more people than ever are crossing borders and living outside their country of birth. Never before has human migration connected so many places of departure and arrival. And whatever country immigrants move to, they overwhelmingly settle in cities.

Migration is propelling urbanization at fast-forward speed. By the year 2000, cities for the first time in human history accounted for half the world's population. The United Nations projects that by 2050 , two thirds of the world's population will live in cities. More than ever, cities are places of diversity - a meeting place of identities of difference.

Increasingly, human and social well-being will depend on whether cities can create an inclusive public culture, home to all. First and foremost, this will require sharing public space.

We know what failure will look like. It won't be pretty, as cities become defined by:

\section{Myer Siemiatycki}

Professor of Politics and Public Administration, Ryerson University

- Residential segregation and ghettos

- Unequal access to institutions and services

- Land use policies that are unresponsive to the distinct residential, recreational, religious and cultural needs of diverse communities

- Recurring spatial reminders of advantage for some and deprivation for others

Such patterns inevitably create polarized and divided cities. Troubled cities.

[see_more]

Conversely, cities can be places of welcome and integration, when they make space for all. This typically benefits not only immigrants and minorities, but the economic, social and cultural position of the entire city.

The city of the future is ours to choose and build. There are many steps - big and small - that can be taken to create cities of inclusion. Some of the most effective and creative are designed to assure that public space (streets, parks,

neighbourhoods), public services (housing, transportation) and public institutions (schools, libraries) serve the entire population.

Leadership can come from many stakeholders. This includes municipal officials, local residents, newcomer communities, local business, labour and media. All it takes is religions, and wanting a city open for all. Fortunately, there are many good examples to consider following.

\section{Inclusive Public Space}

How can public space build belonging in a diverse city? Two factors are especially important. First is being responsive to the distinct needs of immigrant and minority communities. Second is connecting these communities to the majority and other minority populations of the city. These are hallmarks of success stories from around the world.

Here is a sample of notable successes across a variety of public spaces.

Housing. Housing is the first urgent need for immigrants and refugees in their new arrival city. Municipal authorities have launched a number of creative initiatives to meet this challenge. Amsterdam created a 'pop-up' complex of prefab housing project Startblok Riekerhaven housing almost 600 single young adults. Interestingly, half the units are reserved for refugees, the other half for Dutch young adults, especially university students. All residents are required to devote time to 
site maintenance and upkeep. The result is greater networking, acculturation and housing security for newcomers, while Dutch students gain affordable housing and enriched global insight.

In Athens, the City Plaza project converted an abandoned hotel into co-operative housing for 400 people. Residents were intentionally selected from a range of nationalities, religions, and ethnicities. All share responsibility for collective chores including cooking and cleaning. In Berlin, the Refugees Welcome initiative has developed an online platform allowing resident Berliners to offer housing in their own homes to refugees. In addition to housing, this also provides refugees with local hosts able to promote the integration of newcomers. This Berlin project has now been adopted in 13 other countries! As the Berlin co-founder of the project stated: "It's about bringing locals and non-locals together to dialogue, to have a better life for all of them."

Cleveland USA, has identified refugee and immigrant housing as key to the city's own urban revival. Its Dream Neighborhood plan, aims to rehabilitate derelict and foreclosed homes for newcomers settling in the city. Over 100 homes have been restored, now occupied by refugee and immigrant families. In addition to revitalizing residential areas, these newcomers are reviving adjacent commercial streets through thor shopping and entrepreneurial activity.

These cases remind us that newcomer housing can be leveraged to provide broader economic, neighbourhood, and social benefits.

Economic Opportunities. Cities have adopted a number of measures to support immigrant entrepreneurial and business aspirations. The Boston Back Streets Program preserves zoning areas for small commercial and industrial uses in areas typically used by immigrant and minority entrepreneurs. Threatened by gentrification and re-development, Boston officials have recognized the importance of protecting these spaces of newcomer enterprise. In Toronto, the Tower Renewal Project pursues the same goal through mixed-use zoning of apartment towers that are home to many immigrants. Flexible zoning allows space in these towers for commercial purposes, including restaurants and assorted service provision. This has a host of potential benefits including business and job creation, and the convenience of on-site services.

In Turin, city officials have taken steps to assure immigrant entrepreneurial access to Europe's largest open-air market, the Porta Palazzo. Immigrants account for $20 \%$ of those living and working in the market area. As tensions arose between merchants over space in the market, and the neighbourhood's residential population started to decline, city officials recognized the need to support the market as a commercial hub and immigrant economic platform. Consulting with all market entrepreneurs, the city designated business space for all, and required merchants themselves to voluntarily oversee maintenance of the market site. With the market stabilized, the city then promoted a 'Living, Not Leaving' campaign, urging residents to remain in neighbourhood. A vibrant commercial market, with immigrant retailing. Became the glue holding a neighbourhood together.

Parks, Sport, Recreation. Many cities pro-actively use their parks as sites of immigrant integration. In Barcelona, a former hospital site in the Nou Barris district has been transformed into parkgrounds, earning the city an international award for promoting the "integrative task in a rapidly expanding and multi-ethnic quarter of Barcelona". In New York, parks have a mandate to promote immigrant access. They advance this through special outreach to newcomer communities, diversity training for park staff, and diversifying not only park programs but also food menus in park restaurants. In Toronto, the recently launched Mayor's School Cricket Tournament has brought this non-traditional sport into more than 50 schools and many parks in the city.

Identity Space. Newcomers seek to express their identity (religious, ethnic, linguistic) in their new urban setting. Inclusive cities find ways to welcome rather than resist such expressions of belonging. In Marxloh Germany, city officials supported construction of the country's largest mosque, which opened to broad public support. The city consulted widely on the mosque plan which included inter-faith dialogue space, an under-sized minaret, and large windows for ease of transparency. In the Spanish town of Badalona, a request from its Sikh community to hold a religious procession through town streets was first denied, and then approved after town officials required Sikhs to meet with local residents for their support. Formal bridge-building meetings ensued, the request was approved, with public officials and neighbourhood residents participating in the parade.

Libraries. Many cities use their municipal libraries to promote newcomer integration. Typically this includes language and reading circles, providing materials in many languages, as well as settlement services such as employment counselling. The Queens Public Library of New York, is America's largest circulation library system, thanks in part to its immigrant outreach 'New Americans Program'. Particularly creative is the 'Living Library' program developed in Valongo, Portugal. It features a real immigrant telling his or her migration story to an audience, based on the program slogan 'Don't judge a book by its cover'.

Taking It To The Street. Our final good practice shows how great inclusion initiatives can come from urban residents themselves. In Auckland New Zealand, the 'Walking_School Bus' is an ingenious path to integration. Parents and children to walk to their neighbourhood school following a distinct route, picking up more and more participants as they proceed, just like a real motorized bus. In the process, diverse families connect, become familiar, and neighbourhood ties are strengthened. It also puts a neighbourhood's diversity on walking display, every day. 
The Author

Myer Siemiatycki is Professor of Politics and Public Administration at Ryerson University. Myer is the founding past Director of Ryerson's Interdisciplinary MA Program in Immigration and Settlement Studies. His research and publications span the fields of immigration, urban and labour studies. Select achievements include the Distinguished Educator Award, Ontario Institute for Studies in Education (1992); Ryerson Popular Professor Citation, Maclean's Guide to Canadian Universities (2003-2006); Ryerson University Faculty Service Award and Research Domain Leader, the Centre of Excellence for Research on Immigration \& Settlement from 2001 to 2006. In 2012, Siemiatycki was appointed as the first Jack Layton Chair, leading the inaugural Jack Layton Book Club and the Jack Layton School for Youth Leadership.

\section{Recommendations For Policy-Makers}

- All urban residents have a role to play building inclusive cities. Where we live, where we shop, whom we befriend, whom we vote for, and our commitment to share public spaces will shape our cities of the future.

- Civic officials have a special responsibility to assure the city belongs to everyone.

- They must assure that public spaces, services and institutions are equally accessible and beneficial to immigrant communities.

- They must assure that public spaces, services and institutions build connections between all communities and identities in the city.

- The path to civic inclusion consists of steps both big and small, best taken based on the widest stakeholder consultation.

Top

[/see_more] 


\title{
Welcome Ability
}

\author{
By Mahmoud Bakkar
}

\section{By Ayse Özbabacan, Policy Officer, Department for Integration Policy, City of Stuttgart}

\author{
Welcome to Stuttgart, the III City: International, Integrative, and Inclusive
}

A strategy to welcome and embrace newcomers into local communities and their new homes.

"It takes a village to raise a child" is an African saying that municipal offices devoted to welcoming and embracing newcomers into a society have long been aware of and well before the refugee movements of the past three years.

Why? Well, metropolitan cities, and cities with strong economies, in particular, attract people from all over the world. Across the globe, some 200 million people born abroad currently live in cities on both sides of the Atlantic. Demographic mobility and mass migration can substantially change the composition of the local population, creating the challenge for cities to integrate highly heterogeneous and culturally diverse groups into the local community.

The impact of (geo)political developments in the refugee movements in 2015 to Germany, right wing extremism and rising xenophobia have greatly influenced the discourse on immigration, security, and integration policies, influencing public attitudes and the communication between political leaders and immigrants. This is a challenge but at the same time a great opportunity to further the societal development of cities by reflecting on existing integration, diversity and welcoming policies towards newcomers in order to build a new narrative.

\section{Ayse Özbabacan}

Policy Officer, Department for Integration Policy, City of Stuttgart

[see_more]

\section{We Are All Stuttgarters}

The narrative of the city of Stuttgart as the iii-city: international, integrative, and inclusive Stuttgart is an international city. Thanks to the migrants, Stuttgart has been able to maintain its population size of 600.000 inhabitants over the past years. 25 percent of the inhabitants are foreigners, and another 20 percent are naturalized migrants and their children. Hence, in total 45 percent of the Stuttgarters have a so-called migration background. This high share has always been an asset for the city, a richness and diversity that the city is proud of. Moreover, among Stuttgart children and youth below the age of 18 , this proportion increases to 60 percent- a share that will shape the future society. In addition, the city has received more than 8,000 refugees, newcomers accommodated in community housing, most of them come from Syria, Iraq and Afghanistan.

Stuttgart is an integrative city. Integration of immigrants has long been a key issue of the city hall. Since 2001, Stuttgart has followed a holistic strategy, its seminal Pact for Integration, to promote the integration and participation of the migrant population in the main living areas in line with the German population.

The Stuttgart Pact formulates the goals and fields of action of Stuttgart's integration policy ranging from language support over education to intercultural dialogue and refugee integration. Major issues such as education and economic integration can only succeed through the cooperation between different actors and institutions. This approach is called intercultural orientation of the municipal administration and its partners include charitable organizations, businesses, foundations, and voluntary work.

\section{No successful integration without cooperation!}

One key element of the pact is to use the talents and potentials of our migrant population for the development of the society. In the economy, through culture, sport and civic engagement, they are partners and co-producers of our integration work, actively shaping our society. In the context of the current refugee integration work, it is the migrants and their organizations who are the experts in designing measures and activities to accelerate the integration of refugees in Stuttgart.

The diversity of our society is our strength: a driving factor unlocking potential for science, economy, culture and everyday life. Integration work on the local level is people work. People assist newcomers as bridge-builders upon arrival and help 
them integrate into their new communities.

Stuttgart is an inclusive city. "Everyone who lives in Stuttgart, is a Stuttgarter", regardless of his or her passport and ethnic background. This slogan aims to embrace newcomers from all over the world and make Stuttgart their new home. And a good Stuttgarter takes on responsibility for a peaceful and productive living together. Local residents support children and youth from socially disadvantaged families through mentoring at school, in sports and cultural clubs, or volunteering at German language courses offered in refugee housing sites. Currently more than 2,000 mentors in the education sector and more than 3,500 volunteers in the area of refugee aid are helping out as sports buddies, job buddies and welcome buddies to support and guide newcomers around working and living in Stuttgart.

To requote the African saying, "It takes a whole community to raise a child," is to affirm the approach of the Stuttgart Pact. A broad alliance of committed partners are essential to welcoming and integrating newcomers into public life and society.

The following selection of good practices, help tell Stuttgart's story of welcome, integration and inclusion:

\section{Welcome Center Stuttgart: Visit - ask - get a perspective for your future}

The word 'Welcome Culture' (Willkommenskultur) became popular and influential in Germany in recent years - but what is the content that is hidden under this term? Welcoming newcomers is not just saying hello to someone. Welcoming is also about creating a welcoming environment, and therefore also welcome structures.

Back in 2014 the city of Stuttgart and the Stuttgart Region Economic Development Corporation established the Welcome Center Stuttgart initially as a point-of-contact for advisory services for newcomers and skilled professionals from Germany and around the world about living and working in Stuttgart. It promoted Stuttgart as a place where people feel respected and are recognized but also a place where people receive the opportunity to get involved and contribute to social life. The idea to establish a welcome center was inspired by the exchange with US and Canadian cities, the so-called one-stop shop for settlement services in cities like Toronto.

The Center offers services in 12 languages and works on topics ranging from entry and residence requirements, to learning German, to employment, job search, housing and access to community organizations, civil society, associations etc. This is a real asset as it actively involves migration advice services with local employment agencies and other partners, and the expertise they offer on how to match newcomers' talents with the skills needed by local companies. The formula is simple: Visit - Ask - Get a perspective on your future. The Center also hosts information events, has established a new citizens club and trained about 100 welcome buddies to support newcomers. Since October 2014, the center has provided services to around 10,000 clients.

\section{The Stuttgart Model of Refugee Integration}

Stuttgart has lots of experience regarding the reception and integration of refugees, called der Stuttgarter Weg. (the Stuttgarter Way). In the 1990s the city received more than 10000 refugees from the former Yugoslavia. And since the refugee crisis of 2015, Stuttgart has received more than 8000 new refugees. New Stuttgarters regardless of the duration of their stay in the city, these newcomers enrich our society. The reception and accommodation of refugees is seen as a humanitarian task and responsibility.

Der Stuttgarter Weg of refugee integration is characterized by diverse and combined measures and is based on four pillars to accelerate the integration and empowerment of refugees and prevent social exclusion:

- Housing: Decentralised accommodation in collective premises and apartments spread around the city to provide a good infrastructure and promote social and economic integration on the spot.

- Social services: Appropriate services related to daily life issues, education and employment, as well as dedicated support of refugees through welfare organizations that provide housing management and care basically under one roof.

- Volunteer work: Support of voluntary activities (Flüchtlingsfreundeskreise): 41 friends' circles comprising more than 3500 volunteers work with refugees.

- Counseling: Special counseling for returnees

\section{Empowerment of Refugees: Stuttgart Refugee Dialogues}

The German government and many institutions have developed and published information and guides and apps to help refugees settle in Germany and find their way through the bureaucracy jungle. A variety of integration strategies also exist to bring people from different social segments together to assist refugees.

However, there is little experience with starting a real dialogue with the refugees about their expectations around living in Germany and the daily challenges they face. To quote Heinz Bude, a German sociologist:

"To understand the social setting one needs to make people talk about their experiences." 
Open dialogue platforms are designed to create spaces where people can come together, talk and get to know each other and learn about their respective life experiences - refugees, volunteers and especially inhabitants and neighbours of refugee homes. The Department for Integration Policy established conversation circles to promote dialogue and empower refugees to take ownership of their lives in Germany. The Stuttgart Refugee dialogues bring together refugees, social workers, administrative staff and volunteers to talk about daily life expectations and integration measures on the same eyelevel. The dialogues are facilitated by professional moderators and interpreters and provide all parties with opportunities to participate and actively reflect on the quality or shortcomings of available integration strategies. The Stuttgart Refugee Support Group was established to provide volunteer activities and opportunities to refugees and neighbourhood locals to accelerate the integration of refugees i.e. interpreting services, language courses in Arabic, Farsi, Kurdish, Tigrinja etc., cultural and sports activities, catering etc.

What is the benefit of the Stuttgart Refugee dialogues?

- Get-together of different groups, talk and listen to each other.

- First-hand information on living in Germany

- Cooperation with trained intercultural dialog moderators and interpreters

- Appreciation and psychological relief and stabilization

- Development of intercultural and communicative skills

- Community building through dialogue approach

- Dialogue on equal eye footing instead of assessment and instruction

- Learning and living democracy through positive experiences not only through information/calls

- Improvement of mutual cultural understanding in mixed dialogue groups.

\section{The Author}

Ayse Özbabacan is Policy Officer, Department for Integration Policy, City of Stuttgart where she is responsible for the implementation of the integration policy concept the "Stuttgart Pact for Integration" with the focus on intercultural opening of the city administration, migration and women, migration and health and persons with special needs and refugee resettlement.

She is also in charge of the coordination of a German city network on local integration policies working with 30 German cities. From 2006 to 2012 she was in charge of the project coordination of the European Cities Network for Local Integration Policies for Migrants, a network to promote the exchange of innovative best-practices on local integration policies among 35 European cities. Ms. Özbabacan is multilingual, speaking six languages. She has degrees in European studies and law, and a master's degree in European culture from the University of Groningen in the Netherlands. She has spent a one month public policy fellowship at the Transatlantic Academy of The German Marshall Fund of the United States in Washington DC studying local integration policies in selected U.S. cities and is an alumni fellow of the Transatlantic Forum on Migration and Integration

\section{Recommendations:}

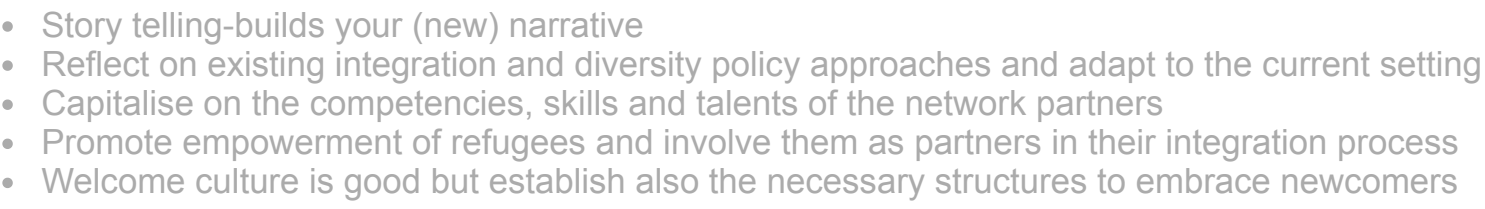

Top

[/see_more] 